\title{
Inflammatory bowel disease: Exploring gut pathophysiology for novel therapeutic targets
}

Vipul Yadav ${ }^{1}$, Felipe Varum ${ }^{2}$, Roberto Bravo ${ }^{2}$, Esther Furrer ${ }^{2}$, Daniela Bojic ${ }^{2}$, Abdul W. Basit ${ }^{1}$

${ }^{1}$ UCL School of Pharmacy, University College London, 29-39 Brunswick Square, London, WC1N1AX, UK

${ }^{2}$ Tillotts Pharma AG, Baslerstrasse 15, CH-4310 Rheinfelden, Switzerland.

\section{Corresponding author:}

Professor Abdul W. Basit

UCL School of Pharmacy

29-39 Brunswick Square

London, WC1N 1AX, UK

Tel.: +44207753 5865; Fax: +44 2077535865 .

E-mail address: a.basit@ucl.ac.uk

Running head: Exploring gut pathophysiology for new targets in IBD

\begin{abstract}
Abbreviations: $\mathrm{UC}=$ Ulcerative Colitis; $\mathrm{CD}=\mathrm{Crohn}$ 's Disease; IL=Interleukin; GALT=Gut Associated Lymphoid Tissue; ADA=Adenosine Deaminase; APC=Antigen Presenting Cells; $\mathrm{NF}_{-\mathrm{K}} \mathrm{B}=$ Nuclear Factor Kappa B; IFN= Interferon; DSS=Dextran Sodium Sulfate; STAT=Signal Activator of Transcription; SMAD-7=Mothers against decapentaplegic homolog 7; $\mathrm{ECP}=$ Eosinophil Cationic Protein; EPX=Eosinophil Protein X; EPO=Eosinophil Peroxidase; CARD=Caspase Recruitment Domain Family Member; TLRs=Toll-Like Receptors; TNF$\alpha=$ Tumor Necrosis Factor Alpha; TGF- $\beta 1=$ Transforming growth factor beta 1 ; iv=Intravenous; $\mathrm{sc}=$ Subcutaneous; il=Intralesional; ic=Intracolonic; $\mathrm{CAM}=$ Cell Adhesion Molecule; ICAM=Intercellular Adhesion Molecule; MAdCAM=Mucosal Vascular Addressin Cell Adhesion Molecule; LPS=Lipopolysaccharides; FcRn=Neonatal Fc Receptor; NKG2D=Natural killer activating receptor 2D; HSP=Heat Shock Proteins; IP-10=Interferon- $\gamma$-Inducible-Protein10; $\mathrm{MCP}=$ Monocyte Chemoattractant Protein; MIP=Macrophage Inflammatory Protein; MMP=Matrix Metalloproteinases; GLP=Glucagon-like Peptide; FMT=Fecal Microbiota Transplantation; HSC=Haematopoietic Stem Cell; MSC=Mesenchymal Stem Cell; PDLIM2=PDZ and LIM Domain 2; PTEN=Phosphatase and Tensin Homolog
\end{abstract}




\section{ABSTRACT}

Ulcerative colitis (UC) and Crohn's disease (CD) are the two major phenotypes of inflammatory bowel disease (IBD), which are influenced by a complex interplay of immunological and genetic elements, though the precise aetiology still remains unknown. With IBD developing into a globally prevailing disease, there is a need to explore new targets and a thorough understanding of the pathophysiological differences between the healthy and diseased gut could unearth new therapeutic opportunities. In this review, we provide an overview of the major aspects of IBD pathogenesis and there after present a comprehensive analysis of the gut pathophysiology leading to a discussion on some of the most promising targets and biological therapies currently being explored. These include various gut proteins (CXCL-10, GATA-3, NKG2D, CD98, microRNAs), immune cells recruited to the gut (mast cells, eosinophils, toll-like receptors 2,4 ), dysregulated proinflammatory cytokines (interleukin-6, -13, -18, -21), and commensal microbiota. We also evaluate some of the emerging non-conventional therapies being explored in IBD treatment focusing on the latest developments in stem cell research, oral targeting of the gut associated lymphoid tissue, novel anti-inflammatory signaling pathway targeting, adenosine deaminase inhibition, and the beneficial effects of anti-oxidant and nutraceutical therapies. In addition, we highlight the growth of biopharmaceuticals and their targets in IBD by providing information on the pre-clinical and clinical development of over 60 biopharmaceutical molecules representing the state of the art in $\mathrm{UC}$ and $\mathrm{CD}$ drug development. 


\section{INTRODUCTION}

Inflammatory bowel disease (IBD) is a chronic relapsing idiopathic inflammatory disorder of the gastrointestinal tract leading to long term impairment of gastrointestinal structure and function [1]. Ulcerative colitis (UC) and Crohn's disease (CD), the two main forms of IBD, share several pathological and clinical symptoms but also have markedly distinct features. In $\mathrm{CD}$, the inflammation and damage to the mucosa can occur throughout the gastrointestinal tract but occurs more commonly in the terminal ileum and colon. It is transmural in nature and can affect all layers of the intestinal tissue. UC on the other hand is confined to the colon, most commonly affecting the rectum and distal colon (often extending from distal to proximal areas as disease progresses) and is characterized by inflammation restricted to the mucosal layer without affecting the deeper layers of the intestinal tissue [2].

Approximately 1.4 million patients in the United States suffer from IBD, of whom around half have UC. Approximately 2.2 million people in Europe suffer from UC and CD [3]. Several factors have been proposed as possible causes of IBD but no single agent or mechanism can fully explain all aspects of the disease aetiology. Some of the proposed factors include environmental, genetic and/or psychological factors, as well as microbial infections and impaired mucosal immune system, which all appear to interact in a way to trigger a dysregulated mucosal immune response leading to chronic inflammation and potential irreversible damage to the gastrointestinal mucosal tissue.

The more conventional therapies for IBD treatment involve aminosalicylates and corticosteroids, generally indicated in mild-moderate condition, and immunosuppressive agents that are indicated in moderate-severe IBD cases. Mesalazine and corticosteroids are the first in line treatment in 
IBD, especially UC, but stable, long term clinical and mucosal healing have not been observed with these agents which have also been associated with adverse effects. The immunosuppressive agents such as azathioprine or 6-mercaptopurine have been implemented to maintain steroid-free treatment, but are not effective in inducing remission and require careful monitoring for adverse effects that include anemia, neutropenia, liver toxicity and pancreatitis [4]. Due to the limitations of efficacy and potential toxicity associated with these drugs, a new generation of biopharmaceuticals such as monoclonal antibodies infliximab, adalimumab, golimumab, certolizumab pegol, natalizumab and vedolizumab have now been introduced in IBD management as more selective therapeutic agents, particularly in moderate to severe cases where the conventional therapies have failed. However, there is a potentially increased risk of malignancies, such as non-Hodgkin's lymphoma and non-melanoma skin cancers and loss of response over time, seen in up to about $50 \%$ of patients on anti-tumor necrosis factor alpha (TNF- $\alpha$ ) antibodies [5]. These limitations highlight the therapeutic gaps in IBD treatment and provide a clear impetus to explore new targets and inflammatory pathways that can potentially direct the development and translation of more efficacious and safer therapeutic agents.

The aim of this review is to give an overview of the pathophysiological changes that occur throughout the gastrointestinal tract in IBD patients and their potential to be exploited as novel targets for the treatment of IBD.

\section{PATHOGENESIS OF IBD}

\section{Immune response}


Both UC and CD have been associated with a defective innate and adaptive immune response, related to responses generated against the commensal microbiota. Activation of macrophages and dendritic cells in the lamina propria stimulates a proinflammatory response by secretion of cytokines such as interferon-gamma (IFN- $\gamma$ ), IL-1 $\beta$, IL-6, IL-8, and IL-18. IL-12 and IL-23 are produced by inflammatory myeloid cells and influence the development of Th1 and IL-17 producing Th17 responses respectively, predominantly being observed in CD pathogenesis [6]. UC pathogenesis has been more associated with an atypical Th2 response characterized by the production of TGF- $\beta$ and IL-5 [7]. Enhanced IL-13 production by an invariant natural killer T cell population in the lamina propria has been shown to be a prominent feature of the inflamed gut, driving inflammation in UC [8,9]. Studies in dextran sodium sulfate (DSS)-induced colitis models and pediatric UC patients have also demonstrated the mucosal overexpression of Th2 signaling molecule GATA-3, a T-cell specific transcription factor, which mediates the subsequent increased mucosal expression of IL-4 and IL-13, and Th1 signaling molecule signal transducer and signal activator of transcription (STAT)-4 proteins, suggesting their involvement in the pathogenesis of UC $[10,11]$. Pronounced infiltration of eosinophils in the mucosal exudates and lamina propria has also been proposed as a potential cause of UC and CD [12]. Eosinophils secrete toxic proinflammatory proteins such as eosinophil cationic protein (ECP), major basic protein, eosinophil protein $\mathrm{X}(\mathrm{EPX})$, eosinophil derived neuroendotoxin and eosinophil peroxidase (EPO). Elevated levels of these proteins in IBD patients damage intestinal tissues, insert pores into membranes of target cells and increase smooth muscle reactivity by generating toxic oxygen radicals [13-17].

\section{Genetic factors}


Many studies based on animal models induced with colitis or transgenic knockout model studies have shed considerable light on the role of multiple genetic mutations as a trigger for IBD. Figure 1 highlights some of the key genes that are involved in the pathogenesis of UC and CD. Mutation of caspase recruitment domain family member 15 (CARD15; formerly NOD2) gene has been shown to be involved in the development of $\mathrm{CD}$. Leucine rich repeat region of CARD15 gene has been identified to have a sole ligand called muramyl dipeptide, a specific motif of peptidoglycan [18], binding to which activates the NF-KB pathway, which regulates the secretion of proinflammatory and protective molecules involved in the homeostasis of intestinal epithelium. Mutations Arg702Trp, Gly908Arg and 1007fs found in the leucine rich repeat domain of CARD15 lead to defective binding with muramyl dipeptide and causes disregulation of $\mathrm{NF}_{-\mathrm{K}} \mathrm{B}$ activation and bacterial recognition. This leads to increased levels of luminal bacteria, decreased clearance of invasive bacteria from epithelial cells and reduced levels of antimicrobial peptides such as $\alpha$-defensins due to the expression of CARD15 in Paneth cells [6]. Mutations in disks large homolog 5 gene, involved in encoding scaffolding proteins which maintain epithelial barrier integrity, has been shown to be associated with CARD15 mutations and ultimately in development of CD [19]. Multi drug resistance gene 1 variants, associated with encoding of Pglycoprotein 170 transporter, have been associated in the pathogenesis of both UC and CD as shown by development of colitis in multi drug resistance gene 1 deficient mice $[6,20]$.

Multiple gene effects in IBD pathogenesis have also been highlighted by several studies that have investigated putative genetic mutations with candidate genes coding for inflammatory cytokines. Polymorphism in the G(-308)A and C(-511)T site of the TNF- $\alpha$ and IL-1 $\beta$ promotor regions respectively leads to impaired cytokine expression and has been suggested to play a role in IBD pathogenesis [21]. Genome-wide association studies have identified and confirmed many 
susceptibility loci for IBD. The most recent and largest study involving genome-wide association data for 75,000 IBD patients identified 163 susceptibility loci, covering 300 potential candidate genes. Of the 163 loci, 110 were a risk to both forms of IBD, while 30 loci were unique to CD and 23 to UC [22]. Further studies are required to understand the involvement of these multiple genetic loci in immunity and inflammation in susceptible individuals.

Genetic factors contribute only partially to general disease variance. It has been suggested that the complex interaction between the human genome, immune system and the intestinal microbiota with external environmental factors such as food, smoking, drugs, breastfeeding and many others plays an important role in IBD pathogenesis. Epigenetics refers to the mitotically heritable modifications in gene expressions, potentially reversible changes in DNA methylation and/or chromatin structure, without alterations in the DNA sequence [23]. DNA methylation is the most studied epigenetic modification correlated to IBD pathogenesis with significant differences in DNA methylation patterns of healthy and inflamed tissues of UC and CD patients. Epigenetic factors may also play a role in the regulation of TNF- $\alpha$ and IL- $1 \beta$ gene expression due to the location of the polymorphism site within a transcription factor AP2 binding site that is sensitive to DNA methylation [21]. Further studies and research in the field of genetic mutations, interaction between genes and epigenetics could not only provide new insights into IBD pathogenesis but may also lead to the development of new medical therapies.

\section{Commensal microbiota}

Bacterial components such as lipopolysaccharides (LPS), peptidoglycans, flagellin and nonmethylated DNA can bind to innate immune cell receptors such as toll-like receptors (TLRs), intestinal epithelial cells (IECs) and mesenchymal cells leading to activation of $\mathrm{NF}-{ }_{\mathrm{K}} \mathrm{B}$ and 
macrophages, stimulating the transcription of proinflammatory cytokines IL-1 $\beta$, IL-6, IL-8, IL12, IL-23, IL-18, TNF- $\alpha$, ROS, nitric oxide and leukotrienes triggering inflammation [6]. Several studies have shown reduced mucosa-associated colonic microbiota diversity in IBD (Table 2). A $50 \%$ and $30 \%$ less diversity has been associated with active CD and UC respectively, confirmed by $16 \mathrm{~S}$ ribosomal RNA gene-based single strand confirmation polymorphism analysis [24]. This state of microbial imbalance and impairment of its functions is called "dysbiosis" and has been proven to play an important role in IBD pathogenesis and complications. The microbial dysbiosis is a result of complex interactions with environmental factors such as diet, smoking, infections and geographical regions as well as genetic modifications associated with IBD susceptibility gene pathways that include microbiota recognition (CARD15 and TLR4), microbial clearance (autophagy genes-ATG16L1, IRGM), immune response (IL-23R, JAK2, TNFSF15) and mucosal barrier function (IBD5) [25]. The impaired bacterial recognition and clearance due to defects in the innate immune response, including neutrophil dysfunction, allows the entry of microbial species into the epithelial cells and a breach in the mucosal integrity forming a major hypothesis for IBD pathogenesis. The uncleared bacteria are walled off in the tissue and a granuloma forms to restrict dissemination of the infective agents. The granulomas secrete proinflammatory cytokines and presents the antigens to adaptive immune system leading to T-cell activation [26]. This drives an inflammatory response which is a hallmark of CD. The defects in bacterial clearance pathway also results in an intense Crohn's like disease in humans called chronic granulomatous disease. The disease is characterized by disorder of the NADPH oxidase system leading to the inability of the phagocytes (neutrophils, macrophages, dendritic cells, mast cells and monocytes) to generate superoxide and consequently result in impaired microbial clearance. 
The repeated bacterial and fungal infections, as well as the formation of granulomas in the tissues are a feature of the disease [27].

There is increasing evidence suggesting the critical role of the interaction between the host's defense system and the commensal microbiota in the pathogenesis of UC and CD, as well as the presence of certain bacterial species such as Escherichia coli, that can bind to the epithelium, and the role of Bacteroides species [28, 29]. Genetic mutations (impaired CARD15, ATG16L1 and IRGM expression) followed by an impaired microbial clearance leads to increased levels of proinflammatory, gram negative adherent-invasive E.coli strains that are able to invade, survive and replicate in host cells, a phenomenon frequently observed in ileal CD patients (Figure 2) [24]. Adherent-invasive E.coli strains adheres to the epithelial cells via the interaction between the type- 1 pili on the surface of the bacteria and carcinoembryogenic antigen-related adhesion molecule 6 which is expressed at the apical surface of enterocytes [30].

\section{Mucus barrier impairment}

The gut bacteria can also interact with the host cells in the small intestine via penetration through the mucus layer, majority of which is removable and very thin and discontinuous in nature, leading to an aberrant immune and inflammatory response in the small intestine [10]. In the colon however, the enormous amount of commensal microbiota resides in a non-adherent outer 'loose' mucus layer, while the firmly 'adherent' inner mucus layer is impermeable to bacteria and thus acts as a protective barrier to the underlying epithelial cell surface and is fundamental in maintaining the homeostasis of the colon $[31,32] . \mathrm{MUC}^{-/-}$mice, as well as colonic biopsies from UC patients, showed lower expression levels of MUC2 glycoprotein [33]. This facilitates bacterial permeation through the inner mucus layer coming in direct contact with the epithelial 
cells to be found deep in the crypts $[32,34]$. Modulations in mucin glycoprotein production and impairments in the colonic inner adherent mucus layer could be one of the key features in UC pathogenesis. CD however is associated with an enhanced expression of mucin glycoproteins MUC2 and MUC3, leading to a thicker mucus layer barrier. Hence the possibility of mucus layer impairment in pathogenesis of CD is not yet well studied. The pathophysiological comparisons of mucus layer in healthy, UC and CD state is shown in Table 2.

\section{B cell activity imbalance}

B cells play an important role in the maintenance of human gastrointestinal immune homeostasis by secreting $\operatorname{IgA}$ and $\operatorname{IgM}$ that protect the epithelial barrier from commensal and pathogenic bacteria, avoiding their permeation into the tissue to cause local and systemic infections [35]. Dysregulations in B cell activity have been shown to exacerbate inflammation by inhibiting regulatory $\mathrm{T}$ cell activity and producing epithelial cell-specific autoantibodies, suggesting that B cell activity imbalance plays a role in mucosal inflammation [36, 37]. Noronha and colleagues have demonstrated an increased tissue B cell activity, elevated surface TLR2 expression and spontaneous IL-8 secretion in CD patients [38]. The increased TLR2 expression in CD positively correlated with disease activity and this could result in patients experiencing higher levels of microbial ligands exposure and enhanced bacterial translocation in the tissue, resulting in the transmural nature of inflammation that is characteristic of CD. However, the increase in B cell activity was not observed in UC patients with increase in disease severity and the properly regulated B cell activation may actually help in reducing clinical symptoms in UC. Therefore, the TLR2+ B cell mediated responses to gut microbiota may play an important role in the 
pathogenesis of $\mathrm{CD}$-associated inflammation and the regulation of its activity might prove to be beneficial in curbing disease symptoms.

\section{Immunoglobulin secretion}

The luminal bacterial antigens also play a central role in the induction and progression of high levels of colonic mucosal immunoglobulins (Ig), mainly $\operatorname{IgA}$ and $\operatorname{IgG}$, in patients with UC and CD compared to healthy state. $\operatorname{IgA}$ is the predominant antibody isotype produced at the intestinal mucosal surfaces and is a critical mediator of mucosal immune response. Recognition of pathogenic bacteria by the intestinal immune system results in production of high-affinity $\operatorname{IgA}$ which is transcytosed into the lumen. These IgA can bind and coat the pathogens to neutralize them, thus protecting the intestine against bacterial penetration and infection [39]. Indigenous bacteria can also stimulate $\operatorname{IgA}$ production and can become coated with $\operatorname{IgA}$. However, the induced $\operatorname{Ig} \mathrm{A}$ response is of low-affinity and specificity, resulting in lower levels of coating compared to pathogenic bacteria. This property of $\operatorname{IgA}$ to coat pathogenic bacteria has been exploited by Palm and colleagues to identify members of the gut microbiota that drive inflammation in IBD [40]. Analyses of the fecal microbiota of UC and CD patients identified 35 bacterial species that were highly coated by $\operatorname{IgA}$, but not in healthy subjects, paving the way for potential targeted antimicrobial therapies in IBD. But maturation defects in B-cells and reduced J-chain expression lead to reduced secretory dimeric IgA and could cause a breakdown in the mucosal homeostasis leading to bacterial invasion and contributing to pathogenesis of IBD [41]. Mucosal secretory IgA concentration has been shown to decrease in IBD patients, suggesting the lack of its barrier protective role in IBD-associated epithelial damage [42]. Ferreira and colleagues also demonstrated that genome-wide association studies of selective IgA deficiency 
showed genes that were also linked to IBD pathogenesis, namely ORMDL3, REL and PTPN22 [43].

CD, associated with a Th1 response, shows an increased level of IgG1, IgG2 and IgG3 subclasses, whereas UC, associated with a Th2 response, shows an increased level of IgG1 and IgG3 subclasses [44, 45]. These increased mucosal IgGs are specifically directed against cytoplasmic, but not to membrane proteins, of commensal microbiota [44]. A specific bacterial antigen flagellin has been shown to induce a pathogenic response in a mouse colitis model mediated by efficient APC activation which requires FcRn-mediated antigen presentation of immune-complexes [46]. However, the mechanisms involved in the interaction between commensal bacteria and our gut immunoglobulins (mainly $\operatorname{IgA}$ and $\mathrm{IgG}$ ) are still very complex and the knowledge of bacterial contribution on the pathogenesis of chronic gut inflammation is still relatively scarce.

\section{External environmental contributors}

The increase in the incidence and prevalence of IBD in the $21^{\text {st }}$ century has led to considerable interest in external environmental factors as important pathogenesis factors in IBD. These factors include diet, smoking and stress [47]. Smoking confers a twofold increase in the risk of CD and is associated with increased reoccurrence after surgery and poorer response to medical therapy. On the contrary, smoking appears to have a protective effect against UC with a halving of the risk in current smokers compared to never smokers. Smoking cessation however is associated with an increased risk of developing UC in susceptible individuals, with the effect lasting up to 10 years post cessation [47]. While the exact mechanism by which smoking exerts its differential effect on UC and CD patients is unclear, recent evidence has suggested the impact of smoking on 
inducing alterations in the microbiota, intestinal permeability and innate and adaptive immune response [48]. Tobacco smoke contains high levels of dioxins, a diverse group of halogenated hydrocarbons, that can have an immunomodulatory effect in humans [49]. These include toxic compounds such as 2,3,7,8-tetrachlorodibenzodioxin and 6-formylindolo (3,2b) carbazole [48]. The aryl hydrocarbon receptor is the only known dioxin receptor and has been recently postulated to play a role in linking environmental factors to host immune system in IBD [49]. However further work is required to fully understand the exact role of this receptor and the chemical complexity of tobacco smoking in the development and progression of IBD.

The role of diet on $\mathrm{UC}$ and $\mathrm{CD}$ pathogenesis remains one of the most challenging associations to study due to its variability with time and difficulty in tracking diet patterns to name a few. Studies conducted by Persson et al. and Reif et al. in 152 CD patients, 145 UC patients and 305 healthy control patients, found an increased risk of CD with high sucrose consumption and lower risk for high fiber consumption $[50,51]$. A significant change in diet has been the increased level of sulphur content. It has been observed in active UC patients that sulphides inhibit the oxidation of n-butyrate analogues which maintains altered intestinal epithelial barrier leading to the development of UC symptoms [52]. UC patients have been shown to have increased numbers of sulfate-reducing bacteria which can interact with luminal substrates to generate sulphoxides that can be highly damaging to the colonic mucosa, emphasizing the hypothesis that sulphur containing diets lead to increased risk of UC [53]. 


\section{CURRENT AND EMERGING BIOLOGICAL THERAPEUTICS FOR IBD}

Biopharmaceuticals are fast gaining priority in the pharmaceutical industry compared to small molecules in both clinical utility and market share. Rapid scientific developments in genomics, proteomics, cell culture and antibody development technologies, as well as increasing knowledge of genetics and cell biology are leading the shift in focus from small molecule therapeutics to biologicals. This is signified by the number of biopharmaceutical patent applications that now exceeds those for small molecules. Reflecting this, of the top 10 highest selling drugs in the world in 2014,7 were biologicals. Their market is estimated to reach $\$ 497.9$ billion by 2020 , growing at $13.5 \%$ compound annual growth rate [54].

Biologicals offer the ability to interact with challenging targets which have thus far eluded small molecule drugs. The emergence of monoclonal antibody therapeutics in particular have revolutionized the treatment of IBD with 4 antibodies against TNF- $\alpha$ and 2 antibodies against cell adhesion molecules currently in the market. However, the increased risk of systemic toxicity and the loss of response over time is forcing scientists to investigate alternative therapeutic targets and biological agents with improved efficacy and safety profile. Some of these emerging biological therapies for IBD in the market and in clinical development, along with their targets and development status have been summarized in table 1. 
1 EXPLORING GUT PATHOPHYSIOLOGICAL CHANGES FOR NOVEL 2 TARGETS IN IBD TREATMENT

3 The gastrointestinal tract is a highly complex environment that undergoes physiological changes

4 under diseased condition. Analyses of these changes not only improves our understanding of the

5 disease pathogenesis, but also presents novel targeting opportunities that can be exploited for the

6 development of new medical therapies. The pathophysiological differences between a healthy

7 and IBD gut have been comprehensively analyzed and summarized in Table 2. Some of the most

8 promising physiological changes being exploited as potential therapeutic targets are discussed

9 thereafter.

\section{Gut proteins and cytokines}

12 An important pathophysiological difference in healthy and inflamed intestine is an enhanced

13 cellular immune response which, in general, is an increased presence of immune cells such as T-

14 cells, M-cells, neutrophils and macrophages (Table 2). The strong cellular immune response

15 translates into an increased level of secretory proinflammatory cytokines that can be inhibited to

16 elicit a potential therapeutic response in IBD. Currently, there are four approved TNF- $\alpha$ cytokine

17 inhibitors available for the treatment of IBD. However, not all IBD patients respond to anti-TNF-

$18 \alpha$ molecules potentially due to polymorphism in the Fc $\gamma$ receptor IIIA gene or formation of anti-

19 drug antibodies, resulting in loss of response over time [55]. Currently there are several new

20 biopharmaceutical agents in clinical stages whose mode of action is inhibition of

21 proinflammatory cytokines and proteins. 
24 IL-13

25 Overexpression of proinflammatory cytokine TNF- $\alpha$ is one of the key pathophysiological 26 features of IBD, and the most targeted cytokine in terms of the currently available and in clinical

27 stage biopharmaceutical therapies in IBD (Table 1). However, other cytokines of the 28 inflammatory cascade that are differentially expressed in UC patients are now being explored as 29 potential new targets. IL-13 from lamina propria mononuclear cells is increased and highly 30 expressed in colonic epithelial cells from UC patients compared to active CD patients and

31 healthy controls, and presents a potential therapeutic target for treatment of UC [56]. NK-T cell

32 type II have been associated with the secretion of IL-13 cytokine as the major source [57], and 33 elimination of NK-T cells along with direct inhibition of IL-13 has been shown to prevent colitis 34 and can be of therapeutic benefit in treatment of IBD [58]. Therapeutic benefit has also been 35 demonstrated in UC by inhibition of IFN- $\beta$ downregulating the production of IL-13 [59]. At 36 present, there are three monoclonal antibodies against IL-13 that have completed phase II clinical 37 trials in UC patients. Tralokinumab, a fully humanized IgG4 antibody against IL-13 did not 38 significantly improve clinical response in UC patients; however, the higher clinical remission 39 rate compared to placebo suggests it may benefit some UC patients [60]. Anrukinzumab, a fully 40 humanized IgG1 antibody to IL-13, did not show statistically significant therapeutic effect in 41 patients with active UC [61].

43 IP-10 (CXCL-10)

44 Overexpression of IP-10 (CXCL-10) in the colonic mucosa of IBD patients, mediated by TLR-3, 45 is being explored as a possible therapy in UC, after IP-10 expression blockade was shown to 46 prevent development of asymptomatic colitis and achieve remission in IL-10 ${ }^{-/-}$mice [62]. A fully 
47 human IP-10 antibody (BMS-936557) has completed a phase II clinical trial in moderate-to-

48 severely active UC patients and showed a significantly higher rate of clinical response compared

49 to placebo along with histological improvements, thus representing a potential candidate for

50 therapy in UC [63]. But significant adverse events and serious infections observed in the trial

51 warrants more safety and tolerability studies for anti-IP-10 therapy.

\section{GATA-3}

54 GATA-3 is a transcription factor which is involved in Th2 mediated immune response process of 55 activation of Th2 cells, signals and cytokine expression, and has been shown to play a role in the 56 pathogenesis of acute phase UC in children [11]. This transcription factor is being explored as a 57 novel therapeutic strategy in UC with an investigative molecule, SB012, currently in clinical 58 phase I/II in UC patients. The product is based on DNAzymes which are chemically synthesized 59 to cleave GATA-3 mRNA and reduce cytokine production, thereby reducing the key features of 60 mucosal inflammatory response in UC [64].

62 MicroRNAs

63 MicroRNAs (miRNAs) are endogenous noncoding RNAs, 22 nucleotides in length that play a

64 role in gene-regulation by binding to the 3'-untranslated regions of the messenger RNAs 65 (mRNAs) of protein-coding genes and destabilize the mRNAs to reduce the target protein output 66 [65]. They are essential regulators of inflammatory signaling pathways like NF-kB [66], and 67 have shown to be differentially expressed in inflammatory conditions like UC [67, 68]. Wu et al. 68 showed 3 miRNAs (miR-192, miR-375, and miR-422b) were significantly down-regulated in 69 active UC tissues whereas 8 miRNAs (miR-16, miR-21, miR-23a, miR-24, miR-29a, miR-126, 
70 miR-195, and Let-7f) were significantly up-regulated in active UC tissues, as compared to

71 healthy tissues [67]. A study by Polytarchou et al. showed an $>8$-fold increased expression of 72 miRNA-214 in particular, in UC colonic tissues, compared to CD and uninflamed tissues [69].

73 The increased expression was correlated to the disease state with enhanced expression in active

74 UC tissues, while no change in inactive UC tissues. The same study also investigated the role of 75 miR-214 on $\mathrm{NF}_{-\mathrm{K}} \mathrm{B}$ phosphorylation activity and the anti-inflammatory effect induced by 76 chemical inhibition of miRNA-214. The miRNA-214 inhibitor was able to significantly suppress

$77 \quad \mathrm{NF}_{-\mathrm{K}} \mathrm{B}$ phosphorylation levels $(>90 \%)$ and the chemical inhibition of miRNA-214 showed 78 suppression of inflammation in a DSS-colitis mouse model as well as in colonic biopsies from

79 UC patients [69], suggesting the therapeutic potential of miRNAs as a novel treatment for IBD.

80 To understand the molecular link between miRNA-214 and UC, 2 genes were identified as direct 81 targets for miRNA-214 in their 3'-untranslated regions, PDZ and LIM domain 2 (PDLIM2) and 82 phosphatase and tensin homolog (PTEN). PDLIM2 is nuclear ubiquitin E3 ligase targeting the 83 p65 subunit of $\mathrm{NF}_{-\mathrm{K}} \mathrm{B}$ and inhibiting its activity [70]. PTEN is a suppressor of AkT signaling 84 pathway that is shown to intervene with $\mathrm{NF}_{-\mathrm{K}} \mathrm{B}$ activation [71], resulting in increased severity of 85 colitis [72]. Overexpression of miRNA-214 suppresses the expression of PDLIM2 and PTEN 86 mRNA and protein levels and induces activation of $\mathrm{NF}_{-\mathrm{K}} \mathrm{B}$ phosphorylation and subsequent IL-6 87 secretion [69]. The STAT-3 transcription factor is able to bind to the promotor region of the 88 miRNA-214 and the presence of IL-6 leads to IL-6-STAT3-dependent miRNA-214 expression 89 and regulation of PDLIM-NF-kB and PTEM-AkT pathways. These results demonstrated the 90 direct involvement of the 2 genes in miRNA-214 regulation of the $\mathrm{NF}_{-\mathrm{K}} \mathrm{B}$ inflammatory response $91 \quad[69]$. 
92 Identification of both UC and CD-associated miRNAs which are differentially expressed in the

93 tissues, as well as understanding of the regulatory role of these miRNAs in acute and chronic

94 inflammatory processes, may lead to the development of miRNAs as effective therapeutic targets

95 for treatment of chronic inflammatory diseases such as IBD.

96

$97 \quad$ TNF- $\alpha$ and CD98

98 Small interfering RNA (siRNA) are double stranded RNA segments ( 20-25 nucleotides in

99 length) which can downregulate the expression of a specific gene at mRNA level, in this case

100 TNF- $\alpha$, a highly expressed proinflammatory cytokine in IBD. Gene silencing and siRNA therapy

101 is currently an exciting area of research exploring its therapeutic role in IBD. One of the major

102 advantages of this therapy could be the local targeting of the siRNA molecules against specific

103 genes in the GI tract via several promising oral delivery systems such as nanoparticles-in-

104 microspheres oral system (NiMOS) [73], thioketal-nanoparticles [74], and cationic cyclodextrin

105 and polyethyleneimine (PEI) vectors [75]. These studies have shown in-vivo in the murine colitis

106 model the ability to deliver the encapsulated siRNA against TNF- $\alpha$ locally, leading to subsequent

107 reduction in TNF- $\alpha$ mRNA levels as well as other proinflammatory mediators (IL-6, IL-1 $\beta$, IL-5,

108 IFN- $\gamma$ and GMCSF) in the colitis tissue via the gene silencing mechanism.

109 CD98 is a $125 \mathrm{kDa}$ type-II transmembrane protein composed of an $80 \mathrm{kDa}$ heavy chain and a

$11040 \mathrm{kDa}$ light chain, involved in amino acid transport, integrin and fusion regulation [76]. CD98

111 also plays a crucial role in regulating intestinal homeostasis and innate immune responses in the

112 gut. CD98 is highly expressed in the IECs and macrophages, potentially upregulated by

113 proinflammatory cytokines [77], and an increased expression has been shown in IBD colonic

114 tissues from mice [78] and humans which can be correlated to the disease state [79]. One 
115 plausible mechanism underlying the contribution of CD98 to intestinal inflammation is the IEC-

116 specific CD98 overexpression resulting in intestinal barrier dysfunction, disruption of

117 homeostatic regulation of cell proliferation and survival and increased intestinal permeability

118 [80]. Thus maintaining low levels of CD98 in IECs in inflamed tissue could have beneficial

119 effects on improving the mucosal barrier function, preventing further tissue damage and could

120 represent a potential therapeutic target for prevention and treatment of IBD. Laroui et al.

121 exploited PEI siRNA molecules to inhibit CD98 expression in DSS-colitis mice colonic tissue

122 via oral delivery in polylactic acid (PLA) nanoparticles [81]. The strategy showed decrease in

123 colitis proving that siRNA-mediated knockdown of CD98 expression could therefore be a

124 promising therapeutic strategy for the treatment of IBD.

125 The studies have shown that there is clinical potential in local treatment of IBD by gene silencing 126 therapy by not only targeting TNF- $\alpha$, but several other overexpressed proteins. However, further

127 studies will be needed to overcome the gastrointestinal luminal, mucosal and cellular barrier in 128 humans.

$130 \quad$ OX40

131 OX40 (CD134) is a member of TNF receptor family expressed by $\mathrm{T}$ cells after ligation of $\mathrm{T}$ cell 132 receptor. OX40 ligand (OX40L) is expressed on APCs, vascular endothelial cells, mast cells, 133 natural killer cells and some $\mathrm{T}$ cells. The OX40-OX40L interaction between $\mathrm{T}$ cell and APC 134 contributes to optimal $\mathrm{T}$ cell function and the generation of memory $\mathrm{T}$ cells, implying its role in 135 sustaining immune response [82]. However, in pathological conditions, as demonstrated in colitis 136 mice models, OX40-OX40L interaction on endothelial cells has been thought to contribute to T 137 cell migration and tissue infiltration, leading to secretion of proinflammatory cytokines via a Th2 
138 response [83]. OX40 also starts to suppress regulatory $\mathrm{T}$ cells leading to imbalances in tolerance

139 and immunity. OX $40^{+} \mathrm{T}$ cells expression has been shown in the lamina propria of colitis mice,

140 compared to normal mice which showed $\mathrm{OX}_{40} 0^{+} \mathrm{T}$ cells only in lymphoid tissue, including

141 Peyer's patches of the gut [84]. OX $40^{+} \mathrm{T}$ cells have also been shown to be highly expressed in 142 the lamina propria of the colon from UC and CD patients [85]. These findings support the role of

143 OX40 signaling in the pathogenesis of IBD. Administration of anti-OX40L monoclonal antibody

144 in colitis mice model has shown to decrease $\mathrm{T}$ cell infiltration into the colon and reduce

145 production of proinflammatory cytokines TNF- $\alpha$, IFN- $\gamma$ and IL-2 in the lamina propria [86].

146 However, the outcomes of altering the OX40-OX40L interactions requires further in-depth

147 investigations before being studied in humans as it can potentially confer serious adverse effects

148 owing to its immunoregulatory role. It is also not clear whether OX40 or OX40L inhibition will

149 lead to the desirable effects in humans. The results of the ongoing phase II study of an anti-OX40

150 monoclonal antibody (KHK4083) to determine the safety in moderate to severe UC patients

151 would answer some of the questions surrounding the potential of OX40 as a therapeutic target in 152 IBD [87].

154 Guanylate cyclase-C

155 Guanylate cyclase-C is a heterodimeric transmembrane enzyme expressed at the apical, brush156 border membranes of intestinal epithelial cells and is distributed along the crypts, villi and 157 mucosal surfaces [88]. Guanylate cyclase-C receptor activation by ligands uroguanylin and 158 guanylin plays an important role in maintaining intestinal mucosal homeostasis and epithelial 159 barrier function by stimulation of cyclic guanosine-3',5'-monophosphate production through 160 cystic fibrosis transmembrane conductance regulator to induce secretion of sodium chloride and 
161 bicarbonate [89]. These electrolytes are critical in the maintenance of the mucus barrier and its

162 interaction with the microbiota. Studies in guanylate cyclase-C and uroguanylin knockout mice

163 model demonstrated a breakdown in the intestinal barrier homeostasis and decreased production

164 of goblet cells and mucin [90]. Guanylate cyclase-C and ligands guanylin and uroguanylin gene

165 expression has also been shown to be downregulated in colon biopsies of UC and CD patients,

166 suggesting a role of guanylate cyclase-C signaling in pathogenesis of IBD [91]. Therefore,

167 guanylate cyclase-C agonists can be exploited as a unique class of therapeutics in IBD

168 management and UC in particular. Shailubhai and colleagues recently reported the therapeutic

169 utility of orally delivered mucosally active guanylate cyclase-C agonist peptides plecanatide and

170 dolcanatide in colitis mice model [92]. The peptides were able to ameliorate inflammation and

171 restore colonic mucosal integrity and homeostasis. Dolcanatide recently completed a phase Ib

172 study in UC patients and was found to be well tolerated. Further studies are warranted to

173 elucidate the precise mechanism by which guanylate cyclase-C agonists promote intestinal

174 barrier function and exert their anti-inflammatory effect.

175

$176 C D$

$177 \quad$ IL-18

178 IL-18 has been shown to be elevated in Th1 mediated CD [93], and an anti-IL-18 strategy has 179 also been explored in murine colitis models where inhibition of IL-18 was shown to suppress

180 IFN- $\gamma$ synthesis and subsequently IL-1 $\beta$ converting enzyme (ICE) synthesis that cleaves IL-1 $\beta$

181 and IL-18 and converts them into active cytokine. Anti-IL-18 strategy also shows suppression of

182 proinflammatory cytokine TNF- $\alpha$ by inhibiting its synthesis and shows potential for a rational 183 strategy in treatment of IBD [94]. 
186 IL-6 is a pleiotropic cytokine that plays a central role in biological activities such as immune 187 regulation, hematopoiesis, inflammation and oncogenesis. IL-6 induces the formation of Th17 188 cells from naïve $\mathrm{T}$ cells together with TGF- $\beta$, and inhibits TGF- $\beta$ induced regulatory $\mathrm{T}$ cell 189 differentiation [95]. The proinflammatory cytokine IL-6 has been shown to bind to cells lacking 190 IL-6 receptor when it forms complexes with the soluble IL-6R. This so-called trans-signaling 191 prevents mucosal and lamina propria T-cell apoptosis and contributes to inflammatory conditions 192 such as observed in CD [96]. This suggests that IL-6 blockade by monoclonal antibodies could 193 prove to be an innovative treatment of CD-associated inflammation. Anti-IL 6 receptor 194 monoclonal antibody has been shown to illicit a clinical effect in active CD [97], and a phase II 195 clinical study is currently ongoing by Pfizer.

198 Between $17 \%$ - 50\% of CD patients have been shown to develop fistulae, a pathological 199 connection between two epithelium-covered organs. Scharl and colleagues demonstrated the 200 association of fistulizing CD with epithelial to mesenchymal transition along with elevated levels 201 of TGF- $\beta$, IL-13 and its receptor IL-13R $\alpha_{1}$ in transitional cells lining the fistulae and in the 202 epithelial cells of deformed crypts adjacent to the fistulae [98]. The findings were somewhat 203 unexpected due to the known association of IL-13 with Th2 cell response linked to UC 204 pathogenesis [99]. TGF- $\beta$ induced epithelial to mesenchymal cell transition by disrupting 
205 epithelial cell formation and IL-13 enabled the epithelial to mesenchymal transition cells to

206 penetrate deeper into the tissue layers. This suggested that a dysregulation of TGF- $\beta / \mathrm{IL}-13$ -

207 induced effects could play a major role in the pathogenesis of CD-associated fistulae. An anti-IL-

20813 antibody was shown to block IL-13 induced events such as STAT6 phosphorylation and

209 SLUG mRNA expression, since both these proteins are strongly expressed in and around CD-

210 associated fistulae and are associated with the invasive potential of transformed epithelial cells

211 [98]. Thus inhibition of IL-13 could provide a novel and successful approach for the treatment of

212 fistulizing CD. An anti-IL-13 monoclonal antibody dectrekumab (QAX-576) developed by

213 Novartis for the treatment of perianal fistulas in CD patients has completed a phase II trial but

214 the results have not yet been published at the time of this review's preparation [100].

217 IL-21 is overexpressed in the inflamed gut of IBD patients (both UC and CD) [101], and 218 targeting of this cytokine can possibly have an impact on both Th1 and Th17 cytokines which are 219 upregulated by IL-21. Fina and colleagues demonstrated amelioration in experimental colitis in 220 wild type mice by targeting IL-21 with a neutralizing IL-21R/Fc fusion protein [102, 103]. An 221 anti-IL-21 antibody developed by Novo Nordisk completed phase II clinical trials in active CD 222 patients to assess safety and efficacy [104]. The results of the trial have not been disclosed yet, 223 however, the company has discontinued further development of the IL-21 antibody therapy for 224 CD. 
227 NKG2D is a known activating receptor on natural killer cells, natural killer $\mathrm{T}$ cells, activated $228 \mathrm{CD} 8^{+} \mathrm{T}$ cells, activated macrophages and $\gamma \delta \mathrm{T}$ cells, which are involved in response to cellular 229 stress such as inflammation and infection. $\mathrm{CD}^{+} \mathrm{T}$ cells expressing NKG2D have been shown to 230 be increased in the lamina propria of $\mathrm{CD}$ patients with an elevated Th1 cytokine profile leading 231 to inflammatory and cytotoxic responses via interaction with ligand MICA or MICB (MHC class 232 I polypeptide-related sequence A or B) [42]. A novel therapeutic target could be the use of 233 specific monoclonal antibodies in blocking of MICA and NKG2D interaction, which has been 234 shown to prevent murine $\mathrm{CD} 4^{+}$T-cell mediated colitis in mice [105], and inhibition of NKG2D 235 receptor, which attenuated disease state in mild but not in severe colitis [106]. However, the 236 results in animal models could not be translated into humans after a phase II study using a human 237 IgG4 anti-NKG2D monoclonal antibody (Novo Nordisk A/S) failed to meet the primary 238 endpoint (reduction in disease activity at week 4 at $2 \mathrm{mg} / \mathrm{kg}$ dose) [107]. The company has 239 discontinued further development of anti-NKG2D as a treatment for CD. Overall the findings 240 suggest a possible role of NKG2D receptor in CD pathogenesis and how its functional inhibition 241 is insufficient to completely inhibit the inflammatory process. However, further clinical 242 development, including dose optimization and frequency for anti-NKG2D therapy is needed.

245 It has been suggested that IL-12 and IL-23 play a role in UC and CD pathogenesis. IL-12 and IL24623 are heterodimeric proteins that share a common p40 subunit, IL-12/23p40 [108]. Targeting of 247 the p40 subunit by monoclonal antibodies has been shown to abrogate colitis in animal models $248[102,109,110]$. Elevated intestinal mucosal levels of IL-12p40 have been observed in IBD 249 patients [109]. Genome-wide association studies have confirmed single nucleotide 
250 polymorphism in IL-12B and IL-23R genes (encoding for IL-12p40 and IL-23, respectively) to

251 be linked with both UC and CD pathogenesis [109, 111]. Due to the genetic association of IL-23

252 pathway in $\mathrm{CD}$, monoclonal antibodies directed against IL-12/23p40 subunit (Ustekinumab,

253 Briakinumab) and IL-23p19 (BI655066) have been investigated as potential therapeutic agents.

254 The safety and efficacy of IL-12/23p40 antagonists has been shown in previous clinical trials for

255 the induction of clinical remission and response in CD patients [112]. However, the inability of

256 briakinumab to meet the primary end-point led to the termination of a phase II trial in CD

257 patients, thus proving there is still much to learn about the pathogenesis of CD [113]. Close

258 attention also needs to be paid to future study designs evaluating IL-12/23p40 antagonists to

259 ensure that suitable end points are chosen to evaluate their true therapeutic potential in CD.

260 Monoclonal antibody against IL-23p19 has also been shown to be effective in both the

261 prevention and treatment of active colitis in mice [114]. Hence, IL-23 has been proposed as an

262 attractive therapeutic target, not only for CD but also in UC treatment. An IL-23 antibody

263 (LY3074828) is currently being tested in a phase II study for clinical efficacy in patients with

264 moderate to severe UC [115].

265

266 IL-17A

267 IL-17 subtype A (IL-17A) is a dimeric glycoprotein with biological functions bridging innate 268 and adaptive immunity [116]. Antibodies to IL-17A (Secukinumab) and IL-17A receptor 269 (Brodalumab) have been evaluated as potential therapeutics [117]. IL-17A and IL-17RA 270 antagonists have proven to be surprisingly ineffective with high rates of adverse effects observed 271 in trials in CD patients, mainly disease worsening [118]. The therapies failed to meet the primary 
272 end point of the trials and had to be terminated. The negative results could be explained by the

273 blocking of IL-17A interfering with its protective function in the perpetuating chronic

274 inflammation by activated T cells in the intestine, as shown in animal models [119]. Problems

275 with trial design, lack of response and persistent gut inflammation associated with polymorphism

276 in tumor necrosis factor-like ligand gene (TL1A) that encodes for cytokine driving pathogenic T

277 cells, were also thought to be the reasons for the unsuccessful trial results [118]. Colombel et al.

278 also hypothesized that worsening of $\mathrm{CD}$ could be linked to $C$. albicans thriving in the gut

279 induced by the loss of control by IL-17 [120].

$281 \quad \mathrm{IFN}-\gamma$

282 Elevated mucosal levels of cytokine IFN- $\gamma$, a type II interferon, have been observed in CD in 283 humans [121, 122]. Strategies aimed at neutralizing IFN- $\gamma$ in CD were therefore explored. 284 Fontolizumab, a humanized form of murine anti-human IFN- $\gamma$ antibody, showed no significant 285 difference in response and remission compared to placebo in a phase II study [123]. Unlike TNF$286 \alpha$, IFN- $\gamma$ does not exist as a membrane bound protein with no in vitro evidence suggesting that 287 target binding by IFN- $\gamma$ antagonists, such as fontolizumab, would result in acute apoptosis of 288 mucosal lymphocytes. IFN- $\gamma$ targeting therapy might have a more gradual onset of action and, 289 with a favorable side effect profile, long half-life and low immunogenicity. Therefore, multiple 290 and more sustained dosing should be considered for maximum benefit [123].

291 These therapeutic failures more importantly highlight the gaps in our understanding of gut 292 pathogenesis of $\mathrm{CD}$ and the limitations in the successful translation of positive data in animal 293 models into effective therapies in humans. 


\section{Mast cells in IBD}

296 Mast cells have long been suspected to play a key role in a variety of chronic inflammatory 297 processes, including the inflammation seen in IBD [124]. Markedly increased number of mast 298 cells have been reported by a number of studies in the mucosa of ileum and colon from IBD 299 patients as compared to healthy volunteers [125, 126]. Mast cell degranulation has been 300 suggested due to higher levels of histamine, tryptase, chymase and carboxypeptidase A levels, as 301 well as proinflammatory cytokines such as TNF- $\alpha$, IL-3, IL-4, IL-5, IL-16 and substance P, both 302 spontaneously and in response to epithelial cell antigens, than do mast cells obtained from 303 normal tissues in healthy subjects or uninflamed tissues from IBD subjects [127, 128]. This 304 significant elevation of mucosal mast cells can be utilized as a potential therapeutic target using 305 pharmacological agents against numerous biologically active molecules secreted by mast cells 306 such as mast cell stabilizer agent cromolyn, ketotifen, $\mathrm{H}_{1}$ receptor antagonists, serotonin 5-HT3 307 receptor antagonist, leuprolide and octreotide acetate [129]. Corticosteroids have also been 308 shown to decrease the number of mast cells [130].

\section{Eosinophils in IBD}

311 Histological findings have shown that the healthy gut mucosa contains and secretes low 312 concentrations of functionally active eosinophils and eosinophil cationic protein (ECP) that 313 protect the host from infectious agents like bacteria, fungi, viruses or parasites [131]. Both

314 inflamed and uninflamed gut mucosa of CD patients have been found to contain significantly

315 higher levels of ECP as compared to healthy gut mucosa. It is interesting to note that the ECP 316 levels in the healthy gut mucosa decrease moving from the terminal ileum to the ascending colon 
317 and the distal colonic segments. However, it has been found that in the gut mucosa of CD

318 affected patients, there is an increase in the levels of ECP towards the distal colonic segments,

319 with peak levels in the transverse colon [131]. Carlson et al. showed the mucosal release of ECP,

320 EPX and EPO to be increased by 10-20 fold while granulocyte macrophage colony-stimulating

321 factor (GM-CSF) and IL-8 levels were 7 fold greater, in patients with UC and proctitis as

322 compared to healthy controls [12]. This pathophysiological difference provides opportunities for

323 new therapeutic interventions in UC and CD by the potential use of electrostatically charged

324 microparticulate delivery systems such as anionic microparticles, nanoparticles or liposomes,

325 which can bind to the elevated levels of positively charged eosinophilic proteins in the gut

326 mucosa of IBD patients. However, the negatively charged mucus layer in the small intestine and

327 colon will also need to be considered during the designing of electrostatically charged delivery

328 systems which need to overcome the mucus barrier.

330 Novel signaling pathway inhibitors in IBD

331 Various anti-inflammatory molecules apart from the biopharmaceuticals currently in clinical

332 phase are being investigated to elicit a potential therapeutic response in IBD by inhibition of 333 signaling pathways which in turn leads to reduced expression of proinflammatory cytokines.

334 Some of these promising molecules have been summarized in Table 3. Probiotic approaches

335 showing promise in inhibition of signaling pathways and potential anti-inflammatory response in 336 IBD have been discussed separately.

\section{Microbiota}

339 Probiotics 
340 Several studies have suggested qualitative changes in indigenous microbiota in the small and

341 large intestine in IBD patients, especially a decrease in the bifidobacteria count. With the help of

342 PCR-assays, quantitative differences in intestinal microbiota have been observed in healthy

343 controls and IBD patients. The variation in microbial species was dependent on the IBD

344 symptoms prevailing in patients. Exploiting these variations by the use of probiotic bacteria like

345 lactobacilli and bifidobacteria has attracted a lot of attention and interest in the field of

346 gastroenterology, especially in inflammatory conditions like IBD. Yan et al. reported two

347 purified proteins, p75 $(75 \mathrm{kDa})$ and $\mathrm{p} 40(40 \mathrm{kDa})$ from probiotic bacterium Lactobacillus

348 rhamnosus $G G$ which promote cell growth and inhibit TNF-induced epithelial cell apoptosis in

349 cultured and in vivo colon models [132]. Lactobacillus rhamnosus $G G$ has shown to induce

350 remission in IBD patients and animal models. However, in a clinical trial designed to test its

351 efficacy as an adjunct to standard maintenance therapy of aminosalicylates, 6-mercaptopurine

352 and corticosteroids in pediatric $\mathrm{CD}$, no significantly beneficial effect was observed [133].

353 VSL\#3 is another probiotic therapy consisting of 450 billion freeze-dried bacteria from 8

354 different strains (Streptococcus thermophilus, Bifidobacterium longum, B. breve, B. infantis,

355 Lactobacillus acidophilus, L. plantarum, L. casei, L. bulgaricus) [134]. VSL\#3 was able to

356 induce significant clinical improvement in relapsing mild-moderate UC patients by protection of

357 epithelial barrier function and reducing apoptosis [134, 135]. Further studies to investigate its

358 effect on microbiota, metabolic profile, cytokine and chemokines expression in inflammatory

359 conditions are currently ongoing (Table 1) [136].

360 Table 4 summarizes some of the promising probiotic strategies that have shown positive results

361 for treatment of IBD. However, there are certain issues related to the delivery, dosing and 
362 survival of probiotic agents that need to be investigated along with further studies in humans to

363 evaluate the true potential of probiotics as a safe and effective treatment option.

365 Fecal microbiota transplantation

366 Fecal microbiota transplantation (FMT) is another strategy being researched that involves the

367 infusion of fecal material from a healthy donor into the gut of a recipient for the treatment of a 368 particular disease. The administration of fecal microbiota is by the upper route 369 (nasogastric/nasojejunal tube or upper endoscopy) or the rectal route (enema or colonoscopy) 370 [137]. The aim of FMT is to restore the microbial balance by introduction of bacteria into the 371 intestinal ecosystem and correction of the dysbiosis. FMT has been shown to be very effective 372 for refractory and recurrent Clostridium difficile infection [138], and could be a promising 373 approach for IBD if the therapy is able to restore the essential components of the microbiota and

374 reverse the inflammatory process. Several case studies have been reported on the success rates of 375 FMT but the assessment of the effectiveness is complicated due to the small number of patients 376 analyzed as part of the study and the lack of detailed analysis of the microbial changes occurring 377 with FMT $[139,140]$. A review by Cammarota and colleagues has collectively presented the 378 FMT studies conducted in UC and CD [141]. The first randomized, placebo-controlled phase II 379 study evaluating the efficacy of FMT in a large population of active UC patients showed that 380 FMT induced remission was significantly greater than placebo, with no difference in adverse 381 effects [142]. Contrary to this result, Rossen et al. showed no clinical and endoscopic remission 382 between UC patients receiving FMT from healthy donors and those receiving their own 383 microbiota. In another study by Vermeire and colleagues, FMT showed higher success rates in 
384 UC (2 out of 8 patients in prolonged remission) than in CD patients (no clinical efficacy 385 observed at week 8) [143]. FMT was suggested to be more efficacious in patients with a more 386 recent diagnosis of UC, as restoring microbial dysbiosis in early disease state might be more 387 plausible. The results were intriguing and the lower response in CD could be explained by the 388 importance of mucosa-adherent bacteria and transmural nature of inflammation, potentially 389 requiring longer treatment cycles. The milder nature of microbial dysbiosis in UC than in CD 390 patients could also lead to easier restoration of the microbial balance [144]. Only a few case

391 series have been described for the management of CD by FMT and in small patient groups.

392 Borody and colleagues showed complete resolution of symptoms in some CD patients treated 393 with rectal FMT [145], while Cui and colleagues demonstrated that FMT input through mid-gut 394 might be the safer and efficient approach in refractory CD [140]. However, in another pilot study 395 in CD patients, no clinical or endoscopic efficacy was observed [146]. Despite FMT being a new 396 and promising research area for IBD treatment, the results are still too fragmentary. Further 397 clinical trials are needed to investigate the clinical efficacy, frequency and duration of 398 administration, dosing regimens, route of delivery, effect of donor on success rates and 399 standardization of microbiota analysis would be needed [25].

$401 \quad$ Toll-like receptors

402 TLR2

403 Toll-like receptors (TLRs) comprise a class of transmembrane pattern recognition receptors 404 which are involved in pathogen recognition, induction of anti-microbial genes, control and 405 initiation of inflammatory and adaptive immune responses [147]. TLRs are expressed by many 
406 cells throughout the gastrointestinal tract such as the IECs [148], and the dendritic cells [149].

407 TLR2 is a member of the TLR family which recognizes the molecular patterns associated with

408 both gram-positive and gram-negative bacteria like lipoproteins and peptidoglycans [149]. TLR2

409 stimulation selectively enhances transepithelial resistance of IECs, inhibits cell apoptosis and 410 preserves the innate immune barrier equilibrium through regulation of tight junctions which

411 maintains mucosal homeostasis against inflammation in IBD. TLR2 expression is barely 412 detectable in a healthy human colon [150], and also remains unchanged in IBD [150]. This loss 413 of function of human TLR2 could be due to selective mutation in TLR2 response of the intestinal 414 epithelium to commensal TLR2-ligands [151]. The Arg753Gln polymorphism silencing TLR2 415 has recently been associated with a pancolitis phenotype in UC patients [152]. The 416 downregulated TLR2 expression in UC patients can be used as an opportunity for developing 417 new therapeutics targeting modulation of barrier-protective TLR2 using exogenous TLR 418 agonists. Cario et al. showed the effect of TLR2 ligand on mucosal inflammation and regulation 419 of epithelial barrier function in DSS-induced murine colitis model [151]. Oral administration of 420 TLR2 ligand PCSK efficiently restored the tight junction integrity of the colitis intestinal 421 epithelium, preventing the entry of luminal antigens and neutrophils and preventing the abnormal 422 immune response and mucosal intestinal inflammation [151]. Ongoing studies may help to 423 understand the regulatory effects of PCSK ligand on the stability and arrangement of tight 424 junction proteins involved in intestinal barrier homeostasis. Further studies on the safety and 425 efficacy of TLR2 agonists in humans would be needed to understand their potential as a therapy 426 in IBD. 
429 TLR4 is known to recognize LPS present in the cell wall of gram-negative bacteria through its

430 co-receptor myeloid differentiation factor-2, which triggers the translocation of $\mathrm{NF}_{-} \mathrm{B}$ pathway

431 and secretion of proinflammatory response [153]. In non-IBD state, TLR4 is expressed at low

432 levels throughout the small and large IECs, but is highly expressed in IBD [126]. This increased 433 expression suggested a potential role of TLR4 in initiation and prolongation of intestinal

434 inflammation, and was thus investigated as a therapeutic target in IBD. An anti-TLR4 antibody 435 therapy was investigated in DSS induced colitis mice model. TLR4 inhibition resulted in 436 amelioration of colitis by decrease in recruitment of antigen presenting cells (APCs) to the 437 lamina propria and reduction in the expression of proinflammatory cytokines TNF- $\alpha$, IL-6, 438 CCL2 and CCL20. However, TLR4 blockade led to defective mucosal healing and impaired 439 epithelial proliferation and is a significant limiting factor in the development of TLR4 440 antagonists in IBD therapy [154]. Further studies are warranted to evaluate the safety and clinical 441 outcomes of TLR4 inhibition due to its regulatory role in maintenance of intestinal homeostasis 442 before studies can be carried out in humans.

444 EMERGING NON-CONVENTIONAL STRATEGIES IN IBD THERAPY 445

446 Restoring pro-regulatory mechanisms

447 Transforming growth factor-beta 1 (TGF- $\beta 1)$ is a regulatory cytokine that plays a key role in 448 maintenance of immunological homeostasis and inflammatory responses. Mucosal TGF- $\beta 1$ has 449 been shown to be abnormally downregulated in active CD patients and the subsequently 450 diminished counter-regulatory TGF- $\beta 1$ response to the inflammatory stimuli has been implicated 451 in CD pathogenesis [155]. This is due to enhanced levels of SMAD7 (Mothers against 
452 decapentaplegic homolog 7), an intracellular protein that binds TGF- $\beta$ receptor and prevents

453 TGF- $\beta 1$-associated and SMAD-associated signaling, leading to SMAD7 as a potential

454 therapeutic target for reducing intestinal inflammation [156]. Mongersen, a 21-base single-strand

455 phosphorothioate antisense oligonucleotide that hybridizes to the human SMAD7 mRNA, 456 facilitates RNase H-mediated RNA degradation. The molecule is delivered locally into the lumen

457 of the terminal ileum and ascending colon in a modified release formulation consisting of $\mathrm{pH}-$ 458 dependent methacrylic acid-ethyl acrylate copolymers; its ability to downregulate SMAD7 and 459 alleviate CD-like colitis was first shown in a mouse model [157]. Successful clinical benefit of 460 SMAD7 targeting by mongersen was shown in a phase II study in 166 active CD patients with a 461 significantly higher rate of clinical response than placebo [158]. The molecule is currently being 462 investigated for efficacy and safety in an ongoing phase III study in active CD patients [159].

463 IL-10 is an anti-inflammatory, immunomodulatory cytokine involved in immune homeostasis, 464 downregulating inflammatory pathway and regulating mucosal inflammation. Defects in IL-10 465 activity may contribute to the development of IBD inflammatory symptoms. Administration of 466 recombinant human IL-10 was found to be ineffective in active CD patients [160]. However, 467 targeting of the IL-10 pathway has shown some promise in mouse models when an antibody468 antigen complex targeted to DEC-205 (a type-I cell surface protein expressed by dendritic cells) 469 has shown to interfere with the function of Th1 cells by an enhanced secretion of IL-10. This 470 modulates the ability of $\mathrm{CD} 4^{+} \mathrm{CXCR}^{+} \mathrm{T}$ cells to migrate to the sites of inflammation via 471 downregulation of CXCR3 expression, preventing autoimmune mediated inflammation in the 472 small intestine and colon [161].

473 IL-4, also an anti-inflammatory and immunoregulatory cytokine, functions by inducing Th2-type $474 \mathrm{CD}^{+} \mathrm{T}$ cells to shift to a Th1 response and is significantly downregulated in IBD. IL-4 gene 
475 therapy (plasmids carrying IL-4 cDNA) in TNBS-induced murine colitis showed promise in

476 reducing disease severity along with reducing the levels of IFN- $\gamma$, TNF- $\alpha$ and IL-6 mRNA [162].

477 However, further studies on the long term effects of pro-regulatory cytokine therapy are needed

478 before application to human studies.

480 Stem cell mediated regeneration of damaged intestinal mucosa

481 In recent years there have been great advances in the knowledge of stem cell therapy and a 482 growing interest in the application of autologous stem cell transplantation in autoimmune 483 diseases including IBD. However, the therapeutic potential of stem cell transplantation requires 484 in-depth investigation along with addressing the practical and ethical issues associated with it. 485 Haematopoietic stem cell (HSC) transplantation and mesenchymal stem cell (MSC) 486 transplantation have shown some promise in patients for treatment of IBD and are currently 487 being evaluated in clinical trials. HSC transplant leads to the generation of a 'new' immune 488 system free of autoimmunity involving preparatory chemotherapy that eliminates the immune 489 system and after HSC transplant, the haematopoietic stem cells generate new tolerant T-cell 490 population [163]. Ditschkowski et al. has reported that 10 out of 11 IBD patients (7 CD patients 491 and 4 UC patients) remained free from the disease after allogeneic HSC transplantation [164].

492 However, the largest randomized clinical trial of HSC transplantation conducted till date in 493 refractory-CD patients showed no significant clinical improvement in inducing sustained disease 494 remission in patients receiving HSC therapy compared to those receiving standard CD treatment 495 [165]. HSC therapy was also associated with significantly more adverse events compared to 496 conventional therapy along with the death of 1 patient. These findings raise serious concerns 497 over the toxicity and lack of clinical efficacy associated with HSC therapy and does not support 
498 the widespread use of HSC transplantation in refractory CD patients. Further research is

499 warranted to study the risk factors associated with the significant toxicity of HSC therapy and to

500 evaluate the possible benefit of maintenance immunosuppressive therapy in patients to regain

501 responsiveness.

502 MSCs inhibit maturation of APCs, T-cell proliferation, IFN- $\gamma$ production and decrease the levels

503 of proinflammatory cytokines IL-6, IL-12 and TNF- $\alpha$ and increase the IL-10 and TGF- $\beta$ levels

504 inducing tolerance and epithelial healing [166]. Adipose-derived MSCs have two biological

505 functions that are useful for the regeneration or repair of damaged tissues, their ability to reduce

506 inflammation and differentiation potential. Following a small phase I trial confirming feasibility

507 and safety of adipose-derived MSCs for the treatment of fistulizing CD, a phase II clinical study

508 evaluating the safety and efficacy of adipose-derived MSCs in combination with fibrin glue in

509 perianal complex fistulas was conducted [167]. Local administration of adipose-derived MSCs

510 with fibrin glue was found to be significantly more effective than fibrin glue alone in the

511 induction of fistulae healing. It also improved the patient's quality of life. Allogeneic adipose-

512 derived MSCs were evaluated in a phase I/IIa study for the treatment of complex perianal

513 fistulizing CD following a local injection [168]. The therapy was found to be promising in terms

514 of the fistulae tract closure, as well as being safe treatment that could potentially overcome the

515 problems associated with surgery and systemic anti-TNFs. Allogeneic adipose-derived MSCs

516 (Cx601) are now being evaluated in a phase III clinical study at a dose of 120 million cells (5

517 million cells/ml) for complex perianal fistulizing CD treatment [169]. Cx601, at a dose of 60

518 million cells ( 5 million cells $/ \mathrm{ml}$ ), is also being evaluated in a phase I/IIa study for safety and

519 efficacy of the treatment to induce remission of moderate active UC [170]. Remestemcel-L

$520\left(\right.$ Prochymal $\left.^{\circledR}\right)$ are MSCs prepared from bone marrow aspirates of healthy human donors. In an 
521 open-label phase II study of remestemcel-L in moderate-to-severe CD patients, 3 out of 9

522 patients showed clinical response by day 14, along with a significant improvement in CD activity

523 index and IBD questionnaire scores at day 28 compared to baseline [171]. Based on these

524 findings, a larger phase III study was initiated, and is currently ongoing, to evaluate the efficacy

525 for the treatment of moderate to severe CD [172]. However, there is a lack of mechanistic data

526 analyzing the effectiveness of the agent in $\mathrm{CD}$, such as the contribution of $\mathrm{T}$ cells/APCs

527 inhibition and the reparative or regenerative effects in the intestinal tissue, raising concerns over

528 the long term application of the therapy [171].

529 The MultiStem ${ }^{\circledR}$ product is a bone marrow derived non-hematopoietic adult adherent stem cell

530 product based on MAPC isolation and extraction protocols. The cells express distinct cytokine

531 profiles, due to different culture conditions, compared to MSCs leading to different phenotypes

532 [173]. The product, believed to reduce inflammation, exert immunomodulatory effects and

533 promote tissue repair, was evaluated for safety and efficacy in a randomized, double-blind,

534 placebo-controlled, phase II clinical trial for the treatment of moderate to severe UC [174]. The

535 product failed to show a significant difference in clinical efficacy compared to placebo in the

536 primary end-points-change in endoscopic score from baseline, as measured by modified Baron

537 score at 8 weeks and change in Mayo rectal bleeding subscore from baseline at 4 and 8 weeks.

538 Several IBD susceptible genes have been identified to explain the potential mechanism of stem

539 cell transplantation being efficient in IBD treatment, which include NOD2/CARD15 expressed in

540 IECs, peripheral blood monocytes and macrophages [175]. Transfer of IBD has been shown in

541 cases where a person develops UC when transplanted with stem cells from sibling with the same

542 disease or development of CD following bone marrow transplantation from donor without CD

543 symptoms but carrying polymorphic forms of IBD susceptible genes NOD2 and CARD15. 
544 Therefore, it is important to note that stem cells that do not carry any polymorphic forms of

545 susceptible IBD genes are important for remission in IBD patients $[2,176]$. Stem cell therapy

546 theoretically appears to be a valuable tool for treatment of IBD but it still remains to be seen

547 further whether it can overcome the issues of safety and show consistent efficacy in larger 548 clinical settings.

\section{Gut associated lymphoid tissue for targeting cytokines}

551 Ochi et al. and Forster et al. investigated the immune modulation of inflammatory diseases by 552 mucosal delivery (oral and nasal) of CD3-specific $\operatorname{IgG} 2$ monoclonal antibody (muromonab-CD3 553 or OKT3) to induce regulatory T-cells that are preferentially induced at mucosal surfaces,

554 secreting IL-10 and TGF- $\beta$, inducing tolerance and avoiding the abnormal mucosal inflammatory 555 reaction by reducing levels of inflammatory cytokines IFN- $\gamma$ and TNF- $\alpha$ associated with IBD $556[177,178]$. Orally delivered CD3-specific antibody at a dose of $5 \mu \mathrm{g}$ was taken up in the gut 557 associated lymphoid tissue (GALT). The oral therapy was found to be superior in action as 558 compared to intravenous delivery, with no depletion of T-cells and apoptosis observed, along 559 with reduced side effects via the oral route. The antibody appears in the gut villi 30 mins to 3 560 hours after oral administration as compared to intravenous delivery in which the antibody 561 appears in the serosal surface of the gut [177]. Oral muromonab-CD3 is currently being 562 evaluated in a phase II study for safety and efficacy in active UC patients [179]. Visilizumab 563 (Facet Biotech) is another investigational humanized IgG2 monoclonal antibody that is in 564 clinical phase targeting the invariant $\mathrm{CD} 3$ chain of the T-cell receptor CD3 to reduce 565 inflammation in severe UC and moderate to severe CD [180, 181]. However, visilizumab 566 (HuM291) at an intravenous dose of $5 \mu \mathrm{g} / \mathrm{kg}$ was not effective in achieving response, remission 
567 or mucosal healing in patients with severe corticosteroid-refractory UC [182]. The patients

568 showed a trend towards a greater rate of colectomy and more prone to symptoms of cytokine 569 release and serious cardiac and vascular disorders. These studies highlight the early stage

570 progress and also the challenges in the translation of CD3 targeting as an effective therapy in

571 UC. The failures in CD3 targeting also challenges our understanding of the pathophysiology of 572 UC.

\section{Adenosine deaminase inhibition}

575 Brown and colleagues have shown a dual mechanism of adenosine deaminase (ADA) inhibition 576 by pentostatin. The first mechanism was by targeting and reducing $\mathrm{T}_{\text {eff }}$ cell numbers and 577 reduction of $\mathrm{T}_{\text {eff }}$ derived cytokines TNF- $\alpha$, IFN- $\gamma$ as well as macrophage-related IL-1 $\beta$ and IL-6. 578 The second mechanism was the potent anti-inflammatory effect of pentostatin, independent of its 579 lymphodepletion effect, showing reduction in IL-1 $\beta$, IL- 6 and TNF- $\alpha$ in a colitis IL-10 ${ }^{-/-}$mouse 580 model [183]. The study demonstrated that ADA might be a potential target for IBD treatment, 581 however further studies investigating safety and efficacy in humans are warranted.

\section{Oxidative/Anti-oxidative balance restoration}

584 It has been previously shown that the macrophages oxidative burst activity is enhanced in IBD 585 condition, leading to production of NADPH oxidase, which then mediates the production of 586 superoxide and other reactive oxygen intermediates such as hydrogen peroxide and hypochlorous 587 acid causing inflammatory conditions [184]. Therefore, anti-oxidants can be potential candidates 588 for anti-inflammatory therapy in IBD by maintaining the balance between reactive oxygen 589 species production and the anti-oxidant property. Phenylethanoid acteoside isolated from 
590 Plantago lanceolata $\mathrm{L}$. has been shown to exhibit anti-oxidative potential and ameliorates acute

591 or chronic inflammation in-vivo in a DSS induced colitis model, along with suppression of 592 proinflammatory cytokine release such as TNF- $\alpha$, IFN- $\gamma$ and GM-CSF [185]. Similarly, other

593 anti-oxidant molecules that have shown promise, mainly in UC, via modulation of oxidant/anti-

594 oxidant balance and reduction in production of iNOS, COX-2 and proinflammatory cytokines

595 such as TNF- $\alpha$ and IL-1ßare Acacia ferruginea [186], Rhizophora apiculata [187], naringin

596 [188], amentoflavone [189], olmesartan medoxomil [190], Lacto-Wolfberry [191], and

597 resveratrol [192].

599 Nutraceutical intervention

600 Supplementation with specific amino acids such as arginine, glutamine, cysteine, threonine, 601 serine, methionine and proline has suggested that they can be useful in mucosal healing and this 602 can possibly lead to their overall beneficial effect in IBD by reducing risk of relapse [193]. Liu et 603 al. demonstrated colonic mucosal healing in DSS-induced colitis rats by administration of a 604 cocktail of supplement amino acids (threonine, methionine and monosodium glutamate) but this 605 mixture of amino acids showed no influence on the mucosal inflammatory status in the same 606 model [194]. Glutamine is an immunomodulatory essential amino acid that has been widely 607 shown to function as an anti-inflammatory agent via several proposed mechanisms, mainly 608 suppression of T cell migration [195], enhancement of heat shock proteins expression [196], 609 endoplasmic reticulum stress signaling, anti-apoptotic effects [197], and by inhibition of NF-KB 610 and STAT signaling pathways [198], leading to reduction of proinflammatory cytokines and 611 subsequent amelioration in inflamed state. Other amino acids that have shown promise are L612 cysteine and L-arginine. L-cysteine was shown to significantly reduce proinflammatory 
613 cytokines TNF- $\alpha$, IL-6, IL-12p40 and IL-1 $\beta$ and increased the expression of caspase-8, inducing 614 apoptosis, in DSS-induced porcine colitis model [199]. L-arginine on the other hand was shown

615 to have anti-inflammatory activity via attenuation of GM-CSF and chemokines C-X-C motif

616 ligand 1 and macrophage inflammatory protein $\alpha$, as well as cytokines IL-1 $\alpha$, IL-1 $1 \beta$, IL-6 as well

617 as IL-17, suggesting a broad role in colitis [200]. Casein glycomacropeptide (169 amino acids) is

618 a C-terminal part of kappa casein that is released in whey during the manufacture of cheese by

619 the action of chymosin. Casein glycomacropeptide can modulate gut microbiota and regulate

620 immune responses and has been considered as a promising candidate for UC treatment [201].

621 Experimental mice colitis model has shown anti-inflammatory effects of casein

622 glycomacropeptide via $\mathrm{NF}_{-\mathrm{K}} \mathrm{B} / \mathrm{p} 65$ pathway inhibition and alleviation of weight loss and

623 morphological/histological damage [202]. In a randomized clinical trial in active distal UC

624 patients, casein glycomacropeptide (fraction of bovine whey protein) as a nutritional therapy was

625 found to be safe and showed a similar disease-modifying effect to that of mesalazine [203].

626

627 Novel cholinergic anti-inflammatory pathway targeting

628 Gallowitsch-Puerta et al. recently discovered a cholinergic anti-inflammatory pathway, which is

629 a rapid and locally acting nervous system based pathway that inhibits cytokine stimulation and

630 response [204]. The signals are transmitted via the vagus nerve, which is the tenth cranial nerve

631 originating in the brain stem and connects brain to the colon through an indirect pathway. The

632 function of the vagus nerve is to maintain balance in the autonomic nervous system by

633 controlling heart rate, blood pressure and digestion. Its main principle neurotransmitter is

634 acetylcholine which modulates organ function by interaction with the peripheral muscarinic

635 receptors. Signals transmitted via this vagus nerve converge with cytokine-producing cells which 
636 express the nicotinic acetylcholine receptor alpha $7(\mathrm{nAChR} \alpha)$, which is an essential component

637 of the cholinergic anti-inflammatory pathway as it inhibits the release of TNF, IL-1 $\beta$, IL-6 and

638 IL-18, but not IL-10. Borovikova et al. showed, in rats, that direct electrical stimulation of this

639 afferent vagus nerve fibres exposed to endotoxins, which activate cytokine release, lead to the

640 inhibition of proinflammatory TNF- $\alpha$ and cytokine release significantly, avoiding the damage to

641 tissues and potential inflammation [205]. The $\alpha-7$ agonists have shown to decrease the activation

642 of NF-KB pathway, a transcription factor which regulates the release of cytokines. This provides

643 an opportunity to exploit this pathway to therapeutic advantage in IBD which is thought to be

644 caused by the excessive cytokine activity leading to inflamed intestinal mucosa.

\section{CONCLUSIONS}

647 The complex and poorly understood aetiology and gut pathophysiology of IBD, as well as 648 discordances in translating results from animal studies to human trials, have restricted the 649 discovery of novel targets and the subsequent therapies from reaching the patients. A 650 comprehensive analysis of the differences in gut pathophysiology in UC and CD patients has 651 presented several gastrointestinal parameters that can potentially be exploited as novel targets for 652 IBD. The exploitation of GATA-3, IP-10 proteins, and TLR inhibitors, currently being 653 investigated in clinical stage, emphasizes on the growing shift from the conventional TNF- $\alpha$ 654 based biologics approaches towards newer targeting opportunities that may represent the future 655 of IBD treatment. Recent developments in emerging therapies such as restoration of pro656 regulatory mechanisms, HSCs and MSCs transplantation and CD3 targeting has shown some 657 potential that requires further trials and in-depth investigation. Ongoing and future explorations 658 and a more insightful understanding of the diseased gut pathology will be an important step 
659 towards the translation of 'promising' targets into clinically effective therapeutics that can

660 revolutionize the treatment of IBD.

661

\section{ACKNOWLEDGMENTS}

663 Conflicts of interest: All authors have read the journal's policy on disclosure of potential 664 conflicts of interest and have none to declare. The authors have also read the journal's authorship 665 agreement.

\section{References}

1. Hanauer, S.B., Inflammatory bowel disease: epidemiology, pathogenesis, and therapeutic 
13. Al-Haddad, S. and R.H. Riddell, The role of eosinophils in inflammatory bowel disease. Gut, 2005. 54(12): p. 1674-5.

14. Makiyama, K., et al., Activation of eosinophils in the pathophysiology of ulcerative colitis. J Gastroenterol, 1995. 30 Suppl 8: p. 64-9.

15. Vivinus-Nebot, M., et al., Functional bowel symptoms in quiescent inflammatory bowel diseases: role of epithelial barrier disruption and low-grade inflammation. Gut, 2014. 63(5): p. 744-52.

16. Wedemeyer, J. and K. Vosskuhl, Role of gastrointestinal eosinophils in inflammatory bowel disease and intestinal tumours. Best Pract Res Clin Gastroenterol, 2008. 22(3): p. 537-49.

17. Bischoff, S.C., J. Grabowsky, and M.P. Manns, Quantification of inflammatory mediators in stool samples of patients with inflammatory bowel disorders and controls. Dig Dis Sci, 1997. 42(2): p. 394-403.

18. Cario, E., Bacterial interactions with cells of the intestinal mucosa: Toll-like receptors and NOD2. Gut, 2005. 54(8): p. 1182-93.

19. Stoll, M., et al., Genetic variation in DLG5 is associated with inflammatory bowel disease. Nat Genet, 2004. 36(5): p. 476-80.

20. Panwala, C.M., J.C. Jones, and J.L. Viney, A novel model of inflammatory bowel disease: mice deficient for the multiple drug resistance gene, mdrla, spontaneously develop colitis. J Immunol, 1998. 161(10): p. 5733-44.

21. Petronis, A. and R. Petroniene, Epigenetics of inflammatory bowel disease. Gut, 2000. 47(2): p. 302-6.

22. McGovern, D.P., S. Kugathasan, and J.H. Cho, Genetics of Inflammatory Bowel Diseases. Gastroenterology, 2015. 149(5): p. 1163-1176 e2.

23. Loddo, I. and C. Romano, Inflammatory Bowel Disease: Genetics, Epigenetics, and Pathogenesis. Front Immunol, 2015. 6: p. 551.

24. Loh, G. and M. Blaut, Role of commensal gut bacteria in inflammatory bowel diseases. Gut Microbes, 2012. 3(6): p. 544-55.

25. Serban, D.E., Microbiota in Inflammatory Bowel Disease Pathogenesis and Therapy: Is It All About Diet? Nutr Clin Pract, 2015. 30(6): p. 760-79.

26. Petersen, H.J. and A.M. Smith, The role of the innate immune system in granulomatous disorders. Front Immunol, 2013. 4: p. 120.

27. Song, E., et al., Chronic granulomatous disease: a review of the infectious and inflammatory complications. Clin Mol Allergy, 2011. 9(1): p. 10.

28. Rath, H.C., et al., Different subsets of enteric bacteria induce and perpetuate experimental colitis in rats and mice. Infect Immun, 2001. 69(4): p. 2277-85.

29. Bloom, S.M., et al., Commensal Bacteroides species induce colitis in host-genotype-specific fashion in a mouse model of inflammatory bowel disease. Cell Host Microbe, 2011. 9(5): p. 390403.

30. Barnich, N., et al., CEACAM6 acts as a receptor for adherent-invasive E. coli, supporting ileal mucosa colonization in Crohn disease. J Clin Invest, 2007. 117(6): p. 1566-74.

31. Atuma, C., et al., The adherent gastrointestinal mucus gel layer: thickness and physical state in vivo. Am J Physiol Gastrointest Liver Physiol, 2001. 280(5): p. G922-9.

32. Johansson, M.E., et al., The inner of the two Muc2 mucin-dependent mucus layers in colon is devoid of bacteria. Proc Natl Acad Sci U S A, 2008. 105(39): p. 15064-9.

33. Dorofeyev, A.E., et al., Mucosal barrier in ulcerative colitis and Crohn's disease. Gastroenterol Res Pract, 2013. 2013: p. 431231.

34. Johansson, M.E., et al., Bacteria penetrate the normally impenetrable inner colon mucus layer in both murine colitis models and patients with ulcerative colitis. Gut, 2014. 63(2): p. 281-91.

35. Brandtzaeg, P., Induction of secretory immunity and memory at mucosal surfaces. Vaccine, 2007. 25(30): p. 5467-84. 
746

747

748

749

750

751

752

753

754

755

756

757

758

759

760

761

762

763

764

765

766

767

768

769

770

771

772

773

774

775

776

777

778

779

780

781

782

783

784

785

786

787

788

789

790

791

792

793

794

795

36. Takahasi, F., et al., Circulating antibodies against human colonic extract enriched with a $40 \mathrm{kDa}$ protein in patients with ulcerative colitis. Gut, 1990. 31(9): p. 1016-20.

37. Olson, T.S., et al., Expanded B cell population blocks regulatory $T$ cells and exacerbates ileitis in a murine model of Crohn disease. J Clin Invest, 2004. 114(3): p. 389-98.

38. Noronha, A.M., et al., Hyperactivated B cells in human inflammatory bowel disease. J Leukoc Biol, 2009. 86(4): p. 1007-16.

39. Yel, L., Selective IgA deficiency. J Clin Immunol, 2010. 30(1): p. 10-6.

40. Palm, N.W., et al., Immunoglobulin A coating identifies colitogenic bacteria in inflammatory bowel disease. Cell, 2014. 158(5): p. 1000-10.

41. Khor, B., A. Gardet, and R.J. Xavier, Genetics and pathogenesis of inflammatory bowel disease. Nature, 2011. 474(7351): p. 307-17.

42. Matricon, J., N. Barnich, and D. Ardid, Immunopathogenesis of inflammatory bowel disease. Self Nonself, 2010. 1(4): p. 299-309.

43. Ferreira, R.C., et al., Association of IFIHI and other autoimmunity risk alleles with selective IgA deficiency. Nat Genet, 2010. 42(9): p. 777-80.

44. Macpherson, A., et al., Mucosal antibodies in inflammatory bowel disease are directed against intestinal bacteria. Gut, 1996. 38(3): p. 365-75.

45. Scott, M.G., et al., Spontaneous secretion of IgG subclasses by intestinal mononuclear cells: differences between ulcerative colitis, Crohn's disease, and controls. Clin Exp Immunol, 1986. 66(1): p. 209-15.

46. Kobayashi, K., et al., An FcRn-dependent role for anti-flagellin immunoglobulin $G$ in pathogenesis of colitis in mice. Gastroenterology, 2009. 137(5): p. 1746-56 e1.

47. Ananthakrishnan, A.N., Environmental risk factors for inflammatory bowel diseases: a review. Dig Dis Sci, 2015. 60(2): p. 290-8.

48. Parkes, G.C., K. Whelan, and J.O. Lindsay, Smoking in inflammatory bowel disease: impact on disease course and insights into the aetiology of its effect. J Crohns Colitis, 2014. 8(8): p. 717-25.

49. Monteleone, I., et al., The aryl hydrocarbon receptor in inflammatory bowel disease: linking the environment to disease pathogenesis. Curr Opin Gastroenterol, 2012. 28(4): p. 310-3.

50. Persson, P.G., A. Ahlbom, and G. Hellers, Diet and inflammatory bowel disease: a case-control study. Epidemiology, 1992. 3(1): p. 47-52.

51. Reif, S., et al., Pre-illness dietary factors in inflammatory bowel disease. Gut, 1997. 40(6): p. 754-60.

52. Roediger, W.E., J. Moore, and W. Babidge, Colonic sulfide in pathogenesis and treatment of ulcerative colitis. Dig Dis Sci, 1997. 42(8): p. 1571-9.

53. Korzenik, J.R., Past and current theories of etiology of IBD: toothpaste, worms, and refrigerators. J Clin Gastroenterol, 2005. 39(4 Suppl 2): p. S59-65.

54. Smart, A.L., S. Gaisford, and A.W. Basit, Oral peptide and protein delivery: intestinal obstacles and commercial prospects. Expert Opin Drug Deliv, 2014. 11(8): p. 1323-35.

55. Vincent, F.B., et al., Antidrug antibodies (ADAb) to tumour necrosis factor (TNF)-specific neutralising agents in chronic inflammatory diseases: a real issue, a clinical perspective. Ann Rheum Dis, 2013. 72(2): p. 165-78.

56. Fuss, I.J., et al., Nonclassical CDId-restricted NK T cells that produce IL-13 characterize an atypical Th2 response in ulcerative colitis. J Clin Invest, 2004. 113(10): p. 1490-7.

57. Pullan, R.D., et al., Thickness of adherent mucus gel on colonic mucosa in humans and its relevance to colitis. Gut, 1994. 35(3): p. 353-9.

58. Monteleone, G., R. Caruso, and F. Pallone, Targets for new immunomodulation strategies in inflammatory bowel disease. Autoimmun Rev, 2014. 13(1): p. 11-4.

59. Liu, X., et al., NF-kappaB signaling regulates functional expression of the MHC class I-related neonatal Fc receptor for IgG via intronic binding sequences. J Immunol, 2007. 179(5): p. 29993011. 
796

797

798

799

800

801

802

803

804

805

806

807

808

809

810

811

812

813

814

815

816

817

818

819

820

821

822

823

824

825

826

827

828

829

830

831

832

833

834

835

836

837

838

839

840

841

842

843

844

60. Danese, S., et al., Tralokinumab for moderate-to-severe UC: a randomised, double-blind, placebo-controlled, phase IIa study. Gut, 2015. 64(2): p. 243-9.

61. Reinisch, W., et al., Anrukinzumab, an anti-interleukin 13 monoclonal antibody, in active UC: efficacy and safety from a phase IIa randomised multicentre study. Gut, 2015. 64(6): p. 894-900.

62. Singh, U.P., et al., CXCL10-producing mucosal CD4+ T cells, NK cells, and NKT cells are associated with chronic colitis in IL-10(-/-) mice, which can be abrogated by anti-CXCL1O antibody inhibition. J Interferon Cytokine Res, 2008. 28(1): p. 31-43.

63. Mayer, L., et al., Anti-IP-10 antibody (BMS-936557) for ulcerative colitis: a phase II randomised study. Gut, 2014. 63(3): p. 442-50.

64. Efficacy, Pharmacokinetics, Tolerability, Safety of SB012 Intrarectally Applied in Active Ulcerative Colitis Patients. www.clinicaltrials.gov/show/NCT02129439, 2015.

65. Guo, H., et al., Mammalian microRNAs predominantly act to decrease target mRNA levels. Nature, 2010. 466(7308): p. 835-40.

66. Boldin, M.P. and D. Baltimore, MicroRNAs, new effectors and regulators of NF-kappaB. Immunol Rev, 2012. 246(1): p. 205-20.

67. Wu, F., et al., MicroRNAs are differentially expressed in ulcerative colitis and alter expression of macrophage inflammatory peptide-2 alpha. Gastroenterology, 2008. 135(5): p. 1624-1635 e24.

68. Koukos, G., et al., MicroRNA-124 regulates STAT3 expression and is down-regulated in colon tissues of pediatric patients with ulcerative colitis. Gastroenterology, 2013. 145(4): p. 842-52 e2.

69. Polytarchou, C., et al., MicroRNA214 is Associated with Progression of Ulcerative Colitis, and Inhibition Reduces Development of Colitis and Colitis-associated Cancer in Mice. Gastroenterology, 2015.

70. Tanaka, T., M.J. Grusby, and T. Kaisho, PDLIM2-mediated termination of transcription factor NF-kappaB activation by intranuclear sequestration and degradation of the p65 subunit. Nat Immunol, 2007. 8(6): p. 584-91.

71. Romashkova, J.A. and S.S. Makarov, NF-kappaB is a target of AKT in anti-apoptotic PDGF signalling. Nature, 1999. 401(6748): p. 86-90.

72. Im, E., et al., Disruption of Pten speeds onset and increases severity of spontaneous colitis in Il10(-/-) mice. Gastroenterology, 2014. 147(3): p. 667-679 e10.

73. Kriegel, C. and M. Amiji, Oral TNF-alpha gene silencing using a polymeric microsphere-based delivery system for the treatment of inflammatory bowel disease. J Control Release, 2011. 150(1): p. 77-86.

74. Wilson, D.S., et al., Orally delivered thioketal nanoparticles loaded with TNF-alpha-siRNA target inflammation and inhibit gene expression in the intestines. Nat Mater, 2010. 9(11): p. 9238.

75. McCarthy, J., et al., Gene silencing of TNF-alpha in a murine model of acute colitis using a modified cyclodextrin delivery system. J Control Release, 2013. 168(1): p. 28-34.

76. Tsumura, H., et al., The role of CD98hc in mouse macrophage functions. Cell Immunol, 2012. 276(1-2): p. 128-34.

77. Fais, S. and F. Pallone, Ability of human colonic epithelium to express the 4F2 antigen, the common acute lymphoblastic leukemia antigen, and the transferrin receptor. Studies in inflammatory bowel disease and after in vitro exposure to different stimuli. Gastroenterology, 1989. 97(6): p. 1435-41.

78. Kucharzik, T., et al., Activation of epithelial CD98 glycoprotein perpetuates colonic inflammation. Lab Invest, 2005. 85(7): p. 932-41.

79. Nguyen, H.T., et al., MicroRNA-7 modulates CD98 expression during intestinal epithelial cell differentiation. J Biol Chem, 2010. 285(2): p. 1479-89.

80. Nguyen, H.T., et al., CD98 expression modulates intestinal homeostasis, inflammation, and colitis-associated cancer in mice. J Clin Invest, 2011. 121(5): p. 1733-47. 
845 81. Laroui, H., et al., Targeting intestinal inflammation with CD98 siRNA/PEI-loaded nanoparticles.

82. Sugamura, K., N. Ishii, and A.D. Weinberg, Therapeutic targeting of the effector T-cell costimulatory molecule OX40. Nat Rev Immunol, 2004. 4(6): p. 420-31.

83. Imura, A., et al., The human OX40/gp34 system directly mediates adhesion of activated T cells to vascular endothelial cells. J Exp Med, 1996. 183(5): p. 2185-95.

84. Higgins, L.M., et al., Regulation of $T$ cell activation in vitro and in vivo by targeting the OX40OX40 ligand interaction: amelioration of ongoing inflammatory bowel disease with an OX40-IgG fusion protein, but not with an OX40 ligand-IgG fusion protein. J Immunol, 1999. 162(1): p. 48693.

85. Stuber, E., et al., The expression of OX40 in immunologically mediated diseases of the gastrointestinal tract (celiac disease, Crohn's disease, ulcerative colitis). Eur J Clin Invest, 2000. 30(7): p. 594-9.

86. Totsuka, T., et al., Therapeutic effect of anti-OX40L and anti-TNF-alpha MAbs in a murine model of chronic colitis. Am J Physiol Gastrointest Liver Physiol, 2003. 284(4): p. G595-603.

87. Study of a Monoclonal Antibody KHK4083 in Moderate Ulcerative Colitis. www.clinicaltrials.gov/show/NCT02647866, 2016.

88. Pitari, G.M., Pharmacology and clinical potential of guanylyl cyclase $C$ agonists in the treatment of ulcerative colitis. Drug Des Devel Ther, 2013. 7: p. 351-60.

89. Forte, L.R., Jr., Uroguanylin and guanylin peptides: pharmacology and experimental therapeutics. Pharmacol Ther, 2004. 104(2): p. 137-62.

90. Han, X., et al., Loss of guanylyl cyclase C (GCC) signaling leads to dysfunctional intestinal barrier. PLoS One, 2011. 6(1): p. e16139.

91. Brenna, O., et al., The guanylate cyclase-C signaling pathway is down-regulated in inflammatory bowel disease. Scand J Gastroenterol, 2015. 50(10): p. 1241-52.

92. Shailubhai, K., et al., Plecanatide and dolcanatide, novel guanylate cyclase-C agonists, ameliorate gastrointestinal inflammation in experimental models of murine colitis. World $\mathrm{J}$ Gastrointest Pharmacol Ther, 2015. 6(4): p. 213-22.

93. Pizarro, T.T., et al., IL-18, a novel immunoregulatory cytokine, is up-regulated in Crohn's disease: expression and localization in intestinal mucosal cells. J Immunol, 1999. 162(11): p. 6829-35.

94. Siegmund, B., et al., Neutralization of interleukin-18 reduces severity in murine colitis and intestinal IFN-gamma and TNF-alpha production. Am J Physiol Regul Integr Comp Physiol, 2001. 281(4): p. R1264-73.

95. Kimura, A. and T. Kishimoto, IL-6: regulator of Treg/Th17 balance. Eur J Immunol, 2010. 40(7): p. $1830-5$.

96. Atreya, R., et al., Blockade of interleukin 6 trans signaling suppresses T-cell resistance against apoptosis in chronic intestinal inflammation: evidence in crohn disease and experimental colitis in vivo. Nat Med, 2000. 6(5): p. 583-8.

97. Ito, H., et al., A pilot randomized trial of a human anti-interleukin-6 receptor monoclonal antibody in active Crohn's disease. Gastroenterology, 2004. 126(4): p. 989-96; discussion 947.

98. Scharl, M., et al., Interleukin-13 and transforming growth factor beta synergise in the pathogenesis of human intestinal fistulae. Gut, 2013. 62(1): p. 63-72.

99. Wynn, T.A., IL-13 effector functions. Annu Rev Immunol, 2003. 21: p. 425-56.

100. A Phase II Efficacy Study in Fistulizing Crohn's Disease Patients www.clinicaltrials.gov/show/NCT01355614, 2015.

101. Monteleone, G., et al., Interleukin-21 enhances T-helper cell type I signaling and interferongamma production in Crohn's disease. Gastroenterology, 2005. 128(3): p. 687-94.

102. Yen, D., et al., IL-23 is essential for T cell-mediated colitis and promotes inflammation via IL-17 and IL-6. J Clin Invest, 2006. 116(5): p. 1310-6. 
895 103. Fina, D., et al., Regulation of gut inflammation and th17 cell response by interleukin-21. Gastroenterology, 2008. 134(4): p. 1038-48.

104. A Randomised, Double-blind, Placebo-controlled, Parallel-group Trial to Assess Clinical Efficacy and Safety of NNC0114-0006 in Subjects With Active Crohn's Disease. www.clinicaltrials.gov/show/NCT01751152, 2015.

105. Ito, Y., et al., Blockade of NKG2D signaling prevents the development of murine CD4+ T cellmediated colitis. Am J Physiol Gastrointest Liver Physiol, 2008. 294(1): p. G199-207.

106. Kjellev, S., et al., Inhibition of NKG2D receptor function by antibody therapy attenuates transferinduced colitis in SCID mice. Eur J Immunol, 2007. 37(5): p. 1397-406.

107. Safety and Efficacy of NNC 0142-0000-0002 in Subjects With Moderately to Severely Active Crohn's Disease. www.clinicaltrials.gov/show/NCT01203631, 2014.

108. Toussirot, E., The IL23/Th17 pathway as a therapeutic target in chronic inflammatory diseases. Inflamm Allergy Drug Targets, 2012. 11(2): p. 159-68.

109. Wang, X., et al., IL12p40 regulates functional development of human CD4+ $T$ cells: enlightenment by the elevated expressions of IL12p40 in patients with inflammatory bowel diseases. Medicine (Baltimore), 2015. 94(10): p. e613.

110. Neurath, M.F., et al., Antibodies to interleukin 12 abrogate established experimental colitis in mice. J Exp Med, 1995. 182(5): p. 1281-90.

914 112. Sandborn, W.J., et al., A randomized trial of Ustekinumab, a human interleukin-12/23 monoclonal antibody, in patients with moderate-to-severe Crohn's disease. Gastroenterology, 2008. 135(4): p. 1130-41.

113. Panaccione, R., et al., Briakinumab for treatment of Crohn's disease: results of a randomized trial. Inflamm Bowel Dis, 2015. 21(6): p. 1329-40.

114. Elson, C.O., et al., Monoclonal anti-interleukin 23 reverses active colitis in a $T$ cell-mediated model in mice. Gastroenterology, 2007. 132(7): p. 2359-70.

115. A Study of LY3074828 in Participants With Moderate to Severe Ulcerative Colitis. www.clinicaltrials.gov/show/NCT02589665, 2016.

116. Gaffen, S.L., Structure and signalling in the IL-17 receptor family. Nat Rev Immunol, 2009. 9(8): p. 556-67.

117. Khanna, R., et al., Anti-IL-12/23p40 antibodies for induction of remission in Crohn's disease. Cochrane Database Syst Rev, 2015. 5: p. CD007572.

118. Hueber, W., et al., Secukinumab, a human anti-IL-17A monoclonal antibody, for moderate to severe Crohn's disease: unexpected results of a randomised, double-blind placebo-controlled trial. Gut, 2012. 61(12): p. 1693-700.

119. Ogawa, A., et al., Neutralization of interleukin-17 aggravates dextran sulfate sodium-induced colitis in mice. Clin Immunol, 2004. 110(1): p. 55-62.

120. Colombel, J.F., et al., Secukinumab failure in Crohn's disease: the yeast connection? Gut, 2013. 62(5): p. 800-1.

121. Breese, E., et al., Interleukin-2- and interferon-gamma-secreting $T$ cells in normal and diseased human intestinal mucosa. Immunology, 1993. 78(1): p. 127-31.

122. Fuss, I.J., et al., Disparate CD4+ lamina propria (LP) lymphokine secretion profiles in inflammatory bowel disease. Crohn's disease LP cells manifest increased secretion of IFNgamma, whereas ulcerative colitis LP cells manifest increased secretion of IL-5. J Immunol, 1996. 157(3): p. 1261-70.

123. Hommes, D.W., et al., Fontolizumab, a humanised anti-interferon gamma antibody, demonstrates safety and clinical activity in patients with moderate to severe Crohn's disease. Gut, 2006. 55(8): p. 1131-7.

124. Barrett, K.E. and D.D. Metcalfe, The mucosal mast cell and its role in gastrointestinal allergic diseases. Clin Rev Allergy, 1984. 2(1): p. 39-53. 
945 125. Raithel, M., et al., Release of mast cell tryptase from human colorectal mucosa in inflammatory

946

947

948

949

950

951

952

953

954

955

956

957

958

959

960

961

962

963

964

965

966

967

968

969

970

971

972

973

974

975

976

977

978

979

980

981

982

983

984

985

986

987

988

989

990

991

992

993

bowel disease. Scand J Gastroenterol, 2001. 36(2): p. 174-9.

126. Nishida, Y., et al., Different distribution of mast cells and macrophages in colonic mucosa of patients with collagenous colitis and inflammatory bowel disease. Hepatogastroenterology, 2002. 49(45): p. 678-82.

127. Galli, S.J., M. Grimbaldeston, and M. Tsai, Immunomodulatory mast cells: negative, as well as positive, regulators of immunity. Nat Rev Immunol, 2008. 8(6): p. 478-86.

128. He, S.H., Key role of mast cells and their major secretory products in inflammatory bowel disease. World J Gastroenterol, 2004. 10(3): p. 309-18.

129. Marshall, J.K. and E.J. Irvine, Ketotifen treatment of active colitis in patients with 5aminosalicylate intolerance. Can J Gastroenterol, 1998. 12(4): p. 273-5.

130. Goldsmith, P., et al., Corticosteroid treatment reduces mast cell numbers in inflammatory bowel disease. Dig Dis Sci, 1990. 35(11): p. 1409-13.

131. Winterkamp, S., M. Raithel, and E.G. Hahn, Secretion and tissue content of eosinophil cationic protein in Crohn's disease. J Clin Gastroenterol, 2000. 30(2): p. 170-5.

132. Yan, F., et al., Soluble proteins produced by probiotic bacteria regulate intestinal epithelial cell survival and growth. Gastroenterology, 2007. 132(2): p. 562-75.

133. Bousvaros, A., et al., A randomized, double-blind trial of Lactobacillus GG versus placebo in addition to standard maintenance therapy for children with Crohn's disease. Inflamm Bowel Dis, 2005. 11(9): p. 833-9.

134. Mennigen, R., et al., Probiotic mixture VSL\#3 protects the epithelial barrier by maintaining tight junction protein expression and preventing apoptosis in a murine model of colitis. Am J Physiol Gastrointest Liver Physiol, 2009. 296(5): p. G1140-9.

135. Tursi, A., et al., Treatment of relapsing mild-to-moderate ulcerative colitis with the probiotic VSL\#3 as adjunctive to a standard pharmaceutical treatment: a double-blind, randomized, placebo-controlled study. Am J Gastroenterol, 2010. 105(10): p. 2218-27.

136. A Prospective, Placebo Controlled, Double-Blind, Cross-over Study on the Effects of a Probiotic Preparation (VSL\#3) on Metabolic Profile, Intestinal Permeability, Microbiota, Cytokines and Chemokines Expression and Other Inflammatory Markers in Pediatric Patients With Crohn's Disease. www.clinicaltrials.gov/show/NCT01632462, 2014.

137. Borody, T.J. and A. Khoruts, Fecal microbiota transplantation and emerging applications. Nat Rev Gastroenterol Hepatol, 2012. 9(2): p. 88-96.

138. van Nood, E., et al., Duodenal infusion of donor feces for recurrent Clostridium difficile. N Engl J Med, 2013. 368(5): p. 407-15.

139. Borody, T.J., et al., Treatment of ulcerative colitis using fecal bacteriotherapy. J Clin Gastroenterol, 2003. 37(1): p. 42-7.

140. Cui, B., et al., Fecal microbiota transplantation through mid-gut for refractory Crohn's disease: safety, feasibility, and efficacy trial results. J Gastroenterol Hepatol, 2015. 30(1): p. 51-8.

141. Cammarota, G., et al., The involvement of gut microbiota in inflammatory bowel disease pathogenesis: potential for therapy. Pharmacol Ther, 2015. 149: p. 191-212.

142. Moayyedi, P., et al., Fecal Microbiota Transplantation Induces Remission in Patients With Active Ulcerative Colitis in a Randomized Controlled Trial. Gastroenterology, 2015. 149(1): p. 102-109 e6.

143. Vermeire, S., et al., Donor Species Richness Determines Faecal Microbiota Transplantation Success in Inflammatory Bowel Disease. J Crohns Colitis, 2015.

144. Erickson, A.R., et al., Integrated metagenomics/metaproteomics reveals human host-microbiota signatures of Crohn's disease. PLoS One, 2012. 7(11): p. e49138.

145. Borody, T.J., et al., Bowel-flora alteration: a potential cure for inflammatory bowel disease and irritable bowel syndrome? Med J Aust, 1989. 150(10): p. 604. 
994

995

996

997

998

999

1000

1001

1002

1003

1004

1005

1006

1007

1008

1009

1010

1011

1012

1013

1014

1015

1016

1017

1018

1019

1020

1021

1022

1023

1024

1025

1026

1027

1028

1029

1030

1031

1032

1033

1034

1035

1036

1037

1038

1039

1040

1041

1042

1043

146. Vermeire, S., et al., Sa1922 Pilot Study on the Safety and Efficacy of Faecal Microbiota Transplantation in Refractory Crohn's Disease. Gastroenterology, 2012. 142(5): p. S-360.

147. Janeway, C.A., Jr. and R. Medzhitov, Innate immune recognition. Annu Rev Immunol, 2002. 20: p. 197-216.

148. Cario, E., et al., Lipopolysaccharide activates distinct signaling pathways in intestinal epithelial cell lines expressing Toll-like receptors. J Immunol, 2000. 164(2): p. 966-72.

149. Hart, A.L., et al., Characteristics of intestinal dendritic cells in inflammatory bowel diseases. Gastroenterology, 2005. 129(1): p. 50-65.

150. Cario, E. and D.K. Podolsky, Differential alteration in intestinal epithelial cell expression of tolllike receptor 3 (TLR3) and TLR4 in inflammatory bowel disease. Infect Immun, 2000. 68(12): p. 7010-7.

151. Cario, E., G. Gerken, and D.K. Podolsky, Toll-like receptor 2 controls mucosal inflammation by regulating epithelial barrier function. Gastroenterology, 2007. 132(4): p. 1359-74.

152. Pierik, M., et al., Toll-like receptor-1, -2, and -6 polymorphisms influence disease extension in inflammatory bowel diseases. Inflamm Bowel Dis, 2006. 12(1): p. 1-8.

153. Park, B.S., et al., The structural basis of lipopolysaccharide recognition by the TLR4-MD-2 complex. Nature, 2009. 458(7242): p. 1191-5.

154. Ungaro, R., et al., A novel Toll-like receptor 4 antagonist antibody ameliorates inflammation but impairs mucosal healing in murine colitis. Am J Physiol Gastrointest Liver Physiol, 2009. 296(6): p. G1167-79.

155. Del Zotto, B., et al., TGF-betal production in inflammatory bowel disease: differing production patterns in Crohn's disease and ulcerative colitis. Clin Exp Immunol, 2003. 134(1): p. 120-6.

156. Monteleone, G., et al., Blocking Smad7 restores TGF-betal signaling in chronic inflammatory bowel disease. J Clin Invest, 2001. 108(4): p. 601-9.

157. Boirivant, M., et al., Inhibition of Smad7 with a specific antisense oligonucleotide facilitates TGF-betal-mediated suppression of colitis. Gastroenterology, 2006. 131(6): p. 1786-98.

158. Monteleone, G., et al., Mongersen, an oral SMAD7 antisense oligonucleotide, and Crohn's disease. N Engl J Med, 2015. 372(12): p. 1104-13.

159. Efficacy and Safety Study of Mongersen (GED-0301) for the Treatment of Subjects With Active Crohn's Disease. www.clinicaltrials.gov/show/NCT02596893, 2016.

160. Fedorak, R.N., et al., Recombinant human interleukin 10 in the treatment of patients with mild to moderately active Crohn's disease. The Interleukin 10 Inflammatory Bowel Disease Cooperative Study Group. Gastroenterology, 2000. 119(6): p. 1473-82.

161. Wadwa, M., et al., IL-10 downregulates CXCR3 expression on Th1 cells and interferes with their migration to intestinal inflammatory sites. Mucosal Immunol, 2016.

162. Xiong, J., et al., Effects of interleukin-4 or interleukin-10 gene therapy on trinitrobenzenesulfonic acid-induced murine colitis. BMC Gastroenterol, 2013. 13: p. 165.

163. van Deen, W.K., A. Oikonomopoulos, and D.W. Hommes, Stem cell therapy in inflammatory bowel disease: which, when and how? Curr Opin Gastroenterol, 2013. 29(4): p. 384-90.

164. Ditschkowski, M., et al., Improvement of inflammatory bowel disease after allogeneic stem-cell transplantation. Transplantation, 2003. 75(10): p. 1745-7.

165. Hawkey, C.J., et al., Autologous Hematopoetic Stem Cell Transplantation for Refractory Crohn Disease: A Randomized Clinical Trial. JAMA, 2015. 314(23): p. 2524-34.

166. Garcia-Bosch, O., E. Ricart, and J. Panes, Review article: stem cell therapies for inflammatory bowel disease - efficacy and safety. Aliment Pharmacol Ther, 2010. 32(8): p. 939-52.

167. Garcia-Olmo, D., et al., Expanded adipose-derived stem cells for the treatment of complex perianal fistula: a phase II clinical trial. Dis Colon Rectum, 2009. 52(1): p. 79-86.

168. de la Portilla, F., et al., Expanded allogeneic adipose-derived stem cells (eASCs) for the treatment of complex perianal fistula in Crohn's disease: results from a multicenter phase I/II a clinical trial. Int J Colorectal Dis, 2013. 28(3): p. 313-23. 
1044 169. Adipose Derived Mesenchymal Stem Cells for Induction of Remission in Perianal Fistulizing

1045

1046

1047

1048

1049

1050

1051

1052

1053

1054

1055

1056

1057

1058

1059

1060 Crohn's Disease (ADMIRE-CD). www.clinicaltrials.gov/show/NCT01541579, 2015.

170. Allogeneic Adipose Tissue-derived Mesenchymal Stem Cells for the Induction of Remission in Ulcerative Colitis (ALOASCU). www.clinicaltrials.gov/show/NCT01914887, 2013.

171. Mannon, P.J., Remestemcel-L: human mesenchymal stem cells as an emerging therapy for Crohn's disease. Expert Opin Biol Ther, 2011. 11(9): p. 1249-56.

172. Evaluation of PROCHYMAL® for Treatment-refractory Moderate-to-severe Crohn's Disease. www.clinicaltrials.gov/show/NCT01233960, 2015.

173. Vaes, B., et al., Application of MultiStem((R)) Allogeneic Cells for Immunomodulatory Therapy: Clinical Progress and Pre-Clinical Challenges in Prophylaxis for Graft Versus Host Disease. Front Immunol, 2012. 3: p. 345.

174. A Study To Investigate The Safety And Possible Clinical Benefit Of Multistem In Patients With Moderate To Severe Ulcerative Colitis. www.clinicaltrials.gov/show/NCT01240915, 2015.

175. Bonen, D.K. and J.H. Cho, The genetics of inflammatory bowel disease. Gastroenterology, 2003. 124(2): p. 521-36.

176. Brittan, M., et al., Bone marrow stem cell-mediated regeneration in IBD: where do we go from here? Gastroenterology, 2007. 132(3): p. 1171-3.

1061

1062

1063

1064

1065

1066

1067

1068

1069

1070

1071

1072

1073

1074

1075

1076

1077

1078

1079

1080

1081

1082

1083

1084

1085

1086

1087

1088

1089

Ochi, H., et al., Oral CD3-specific antibody suppresses autoimmune encephalomyelitis by inducing CD4+CD25- LAP + T cells. Nat Med, 2006. 12(6): p. 627-35.

178. Forster, K., et al., An oral CD3-specific antibody suppresses T-cell-induced colitis and alters cytokine responses to T-cell activation in mice. Gastroenterology, 2012. 143(5): p. 1298-307.

179. Oral OKT3 for the Treatment of Active Ulcerative Colitis. www.clinicaltrials.gov/show/NCT01287195, 2013.

180. Ulcerative Colitis Study: Study of Visilizumab in Patients With Severe Ulcerative Colitis. www.clinicaltrials.gov/show/NCT00267306, 2012.

181. Visilizumab for Moderate to Severe Inflammatory, Nonstricturing, Nonpenetrating Crohn's Disease. www.clinicaltrials.gov/show/NCT00267722, 2012.

182. Sandborn, W.J., et al., Anti-CD3 antibody visilizumab is not effective in patients with intravenous corticosteroid-refractory ulcerative colitis. Gut, 2010. 59(11): p. 1485-92.

183. Brown, J.B., et al., Therapeutic benefit of pentostatin in severe IL-10-/- colitis. Inflamm Bowel Dis, 2008. 14(7): p. 880-7.

184. Hausmann, M., et al., Subtractive screening reveals up-regulation of NADPH oxidase expression in Crohn's disease intestinal macrophages. Clin Exp Immunol, 2001. 125(1): p. 48-55.

185. Hausmann, M., et al., In vivo treatment with the herbal phenylethanoid acteoside ameliorates intestinal inflammation in dextran sulphate sodium-induced colitis. Clin Exp Immunol, 2007. 148(2): p. 373-81.

186. Sakthivel, K.M. and C. Guruvayoorappan, Protective effect of Acacia ferruginea against ulcerative colitis via modulating inflammatory mediators, cytokine profile and NF-kappaB signal transduction pathways. J Environ Pathol Toxicol Oncol, 2014. 33(2): p. 83-98.

187. V, V.P. and G. C, Protective effect of marine mangrove Rhizophora apiculata on acetic acid induced experimental colitis by regulating anti-oxidant enzymes, inflammatory mediators and nuclear factor-kappa B subunits. Int Immunopharmacol, 2014. 18(1): p. 124-34.

188. Kumar, V.S., et al., Naringin ameliorates acetic acid induced colitis through modulation of endogenous oxido-nitrosative balance and DNA damage in rats. J Biomed Res, 2014. 28(2): p. 132-45.

1090

1091

1092

1093

189. Sakthivel, K.M. and C. Guruvayoorappan, Amentoflavone inhibits iNOS, COX-2 expression and modulates cytokine profile, NF-kappaB signal transduction pathways in rats with ulcerative colitis. Int Immunopharmacol, 2013. 17(3): p. 907-16.

190. Nagib, M.M., et al., Anti-inflammatory and anti-oxidant activities of olmesartan medoxomil ameliorate experimental colitis in rats. Toxicol Appl Pharmacol, 2013. 271(1): p. 106-13. 
1094

1095

1096

1097

1098

1099

1100

1101

1102

1103

1104

1105

1106

1107

1108

1109

1110

1111

1112

1113

1114

1115

1116

1117

1118

1119

1120

1121

1122

1123

1124

1125

1126

1127

1128

1129

1130

1131

1132

1133

1134

1135

1136

1137

1138

1139

1140

1141

1142

191. Philippe, D., et al., Anti-inflammatory effects of Lacto-Wolfberry in a mouse model of experimental colitis. World J Gastroenterol, 2012. 18(38): p. 5351-9.

192. Yao, J., et al., Anti-oxidant effects of resveratrol on mice with DSS-induced ulcerative colitis. Arch Med Res, 2010. 41(4): p. 288-94.

193. Lan, A., et al., Mucosal Healing in Inflammatory Bowel Diseases: Is There a Place for Nutritional Supplementation? Inflamm Bowel Dis, 2014.

194. Liu, X., et al., Beneficial effects of an amino acid mixture on colonic mucosal healing in rats. Inflamm Bowel Dis, 2013. 19(13): p. 2895-905.

195. Hou, Y.C., et al., Glutamine supplementation attenuates expressions of adhesion molecules and chemokine receptors on T cells in a murine model of acute colitis. Mediators Inflamm, 2014. 2014: p. 837107.

196. Xue, H., A.J. Sufit, and P.E. Wischmeyer, Glutamine therapy improves outcome of in vitro and in vivo experimental colitis models. JPEN J Parenter Enteral Nutr, 2011. 35(2): p. 188-97.

197. Crespo, I., et al., Glutamine treatment attenuates endoplasmic reticulum stress and apoptosis in TNBS-induced colitis. PLoS One, 2012. 7(11): p. e50407.

198. Kretzmann, N.A., et al., Effects of glutamine on proinflammatory gene expression and activation of nuclear factor kappa $B$ and signal transducers and activators of transcription in TNBSinduced colitis. Inflamm Bowel Dis, 2008. 14(11): p. 1504-13.

199. Kim, C.J., et al., L-cysteine supplementation attenuates local inflammation and restores gut homeostasis in a porcine model of colitis. Biochim Biophys Acta, 2009. 1790(10): p. 1161-9.

200. Coburn, L.A., et al., L-arginine supplementation improves responses to injury and inflammation in dextran sulfate sodium colitis. PLoS One, 2012. 7(3): p. e33546.

201. Requena, P., et al., Bovine glycomacropeptide ameliorates experimental rat ileitis by mechanisms involving downregulation of interleukin 17. Br J Pharmacol, 2008. 154(4): p. 825-32.

202. Chen, Q., et al., Anti-apoptotic effects of milk-derived casein glycomacropeptide on mice with ulcerative colitis. Food and Agricultural Immunology, 2014. 25(4): p. 453-466.

203. Wernlund, P.G., et al., MON-PP058: Randomised Clinical Trial: Casein Glycomacropeptide for Active Distal Ulcerative Colitis \&\#x2013; A Pilot Study. Clinical Nutrition, 2015. 34: p. S149.

204. Gallowitsch-Puerta, M. and K.J. Tracey, Immunologic role of the cholinergic anti-inflammatory pathway and the nicotinic acetylcholine alpha 7 receptor. Ann N Y Acad Sci, 2005. 1062: p. 20919.

205. Borovikova, L.V., et al., Vagus nerve stimulation attenuates the systemic inflammatory response to endotoxin. Nature, 2000. 405(6785): p. 458-62.

206. McConnell, E.L., H.M. Fadda, and A.W. Basit, Gut instincts: explorations in intestinal physiology and drug delivery. Int J Pharm, 2008. 364(2): p. 213-26.

207. Nugent, S.G., et al., Intestinal luminal pH in inflammatory bowel disease: possible determinants and implications for therapy with aminosalicylates and other drugs. Gut, 2001. 48(4): p. 571-7.

208. Ewe, K., et al., Inflammation does not decrease intraluminal pH in chronic inflammatory bowel disease. Dig Dis Sci, 1999. 44(7): p. 1434-9.

209. Press, A.G., et al., Gastrointestinal pH profiles in patients with inflammatory bowel disease. Aliment Pharmacol Ther, 1998. 12(7): p. 673-8.

210. Sinha, A., et al., Intestinal Performance of Two Mesalamine Formulations in Patients with Active Ulcerative Colitis as Assessed by Gamma Scintigraphy. Practical Gastrotenterology, 2003: p. 5669.

211. Fallingborg, J., P. Pedersen, and B.A. Jacobsen, Small intestinal transit time and intraluminal $p H$ in ileocecal resected patients with Crohn's disease. Dig Dis Sci, 1998. 43(4): p. 702-5.

212. Hebden, J.M., et al., Limited exposure of the healthy distal colon to orally-dosed formulation is further exaggerated in active left-sided ulcerative colitis. Aliment Pharmacol Ther, 2000. 14(2): p. $155-61$. 
1143 213. Sartor, R.B., Microbial influences in inflammatory bowel diseases. Gastroenterology, 2008. 134(2): p. 577-94.

214. Sokol, H., et al., Faecalibacterium prausnitzii is an anti-inflammatory commensal bacterium identified by gut microbiota analysis of Crohn disease patients. Proc Natl Acad Sci U S A, 2008. 105(43): p. 16731-6.

215. Willing, B.P., et al., A pyrosequencing study in twins shows that gastrointestinal microbial profiles vary with inflammatory bowel disease phenotypes. Gastroenterology, 2010. 139(6): p. 1844-1854 e1.

216. Jung, Y. and Y.M. Kim, What should be considered on design of a colon-specific prodrug? Expert Opin Drug Deliv, 2010. 7(2): p. 245-58.

217. Im, E., et al., Elevated lipopolysaccharide in the colon evokes intestinal inflammation, aggravated in immune modulator-impaired mice. Am J Physiol Gastrointest Liver Physiol, 2012. 303(4): p. G490-7.

218. Horrigan, F.D. and S.H. Danovitch, The origin of human fecal alkaline phosphatase. Am J Dig Dis, 1974. 19(7): p. 603-8.

219. Tuin, A., et al., Role of alkaline phosphatase in colitis in man and rats. Gut, 2009. 58(3): p. 37987.

220. McGuckin, M.A., et al., Intestinal barrier dysfunction in inflammatory bowel diseases. Inflamm Bowel Dis, 2009. 15(1): p. 100-13.

221. Hollander, D., et al., Increased intestinal permeability in patients with Crohn's disease and their relatives. A possible etiologic factor. Ann Intern Med, 1986. 105(6): p. 883-5.

222. Ramasundara, M., et al., Defensins and inflammation: the role of defensins in inflammatory bowel disease. J Gastroenterol Hepatol, 2009. 24(2): p. 202-8.

223. Secondulfo, M., et al., Intestinal permeability in Crohn's disease patients and their first degree relatives. Dig Liver Dis, 2001. 33(8): p. 680-5.

224. Wehkamp, J., et al., Reduced Paneth cell alpha-defensins in ileal Crohn's disease. Proc Natl Acad Sci U S A, 2005. 102(50): p. 18129-34.

225. McAulfy, R.L. and S.C. Sommers, Mast Cells in Nonspecific Ulcerative Colitis. American Journal of Digestlve Diseases, 1961. 6(3): p. 233-236.

226. Dvorak, A.M. and G.R. Dickersin, Crohn's disease: transmission electron microscopic studies. I. Barrier function. Possible changes related to alterations of cell coat, mucous coat, epithelial cells, and Paneth cells. Hum Pathol, 1980. 11(5 Suppl): p. 561-71.

227. Tirosh, B., et al., Transferrin as a luminal target for negatively charged liposomes in the inflamed colonic mucosa. Mol Pharm, 2009. 6(4): p. 1083-91.

228. Leon, A.J., et al., High Levels of Proinflammatory Cytokines, but Not Markers of Tissue Injury, in Unaffected Intestinal Areas from Patients with IBD. Mediators of Inflammation, 2009. 2009: p. 110.

229. Levy, A.M., et al., Increased eosinophil granule proteins in gut lavage fluid from patients with inflammatory bowel disease. Mayo Clin Proc, 1997. 72(2): p. 117-23.

230. Uguccioni, M., et al., Increased expression of IP-10, IL-8, MCP-1, and MCP-3 in ulcerative colitis. Am J Pathol, 1999. 155(2): p. 331-6.

231. West, G.A., et al., Interleukin 4 in inflammatory bowel disease and mucosal immune reactivity. Gastroenterology, 1996. 110(6): p. 1683-95.

232. Haas, S.L., et al., Interleukin-18 serum levels in inflammatory bowel diseases: correlation with disease activity and inflammatory markers. Swiss Med Wkly, 2009. 139(9-10): p. 140-5.

233. Keates, A.C., et al., Interleukin 16 is up-regulated in Crohn's disease and participates in TNBS colitis in mice. Gastroenterology, 2000. 119(4): p. 972-82.

234. Kelly, P., et al., Vitamin D status and cytokine levels in patients with Crohn's disease. Int J Vitam Nutr Res, 2011. 81(4): p. 205-10. 
1192

1193

1194

1195

1196

1197

1198

1199

1200

1201

1202

1203

1204

1205

1206

1207

1208

1209

1210

1211

1212

1213

1214

1215

1216

1217

1218

1219

1220

1221

1222

1223

1224

1225

1226

1227

1228

1229

1230

1231

1232

1233

1234

1235

1236

1237

1238

1239

235. Ostvik, A.E., et al., Enhanced expression of CXCL10 in inflammatory bowel disease: potential role of mucosal Toll-like receptor 3 stimulation. Inflamm Bowel Dis, 2013. 19(2): p. 265-74.

236. Allez, M., et al., CD4+NKG2D+T cells in Crohn's disease mediate inflammatory and cytotoxic responses through MICA interactions. Gastroenterology, 2007. 132(7): p. 2346-58.

237. Godkin, A.J., et al., Expression of nitric oxide synthase in ulcerative colitis. Eur J Clin Invest, 1996. 26(10): p. 867-72.

238. Tarlton, J.F., et al., The role of up-regulated serine proteases and matrix metalloproteinases in the pathogenesis of a murine model of colitis. Am J Pathol, 2000. 157(6): p. 1927-35.

239. Meijer, M.J., et al., Increased mucosal matrix metalloproteinase-1, -2, -3 and -9 activity in patients with inflammatory bowel disease and the relation with Crohn's disease phenotype. Dig Liver Dis, 2007. 39(8): p. 733-9.

240. Rafa, H., et al., IL-23/IL-17A axis correlates with the nitric oxide pathway in inflammatory bowel disease: immunomodulatory effect of retinoic acid. J Interferon Cytokine Res, 2013. 33(7): p. 355-68.

241. Bustos, D., et al., Colonic proteinases: increased activity in patients with ulcerative colitis. Medicina (B Aires), 1998. 58(3): p. 262-4.

242. Midtvedt, T., et al., Increase of faecal tryptic activity relates to changes in the intestinal microbiome: analysis of Crohn's disease with a multidisciplinary platform. PLoS One, 2013. 8(6): p. e66074.

243. Hu, S., et al., Translational inhibition of colonic epithelial heat shock proteins by IFN-gamma and TNF-alpha in intestinal inflammation. Gastroenterology, 2007. 133(6): p. 1893-904.

244. Midura-Kiela, M.T., et al., Curcumin inhibits interferon-gamma signaling in colonic epithelial cells. Am J Physiol Gastrointest Liver Physiol, 2012. 302(1): p. G85-96.

245. Singh, S. and B.B. Aggarwal, Activation of transcription factor NF-kappa B is suppressed by curcumin (diferuloylmethane) [corrected]. J Biol Chem, 1995. 270(42): p. 24995-5000.

246. Chen, Y.R. and T.H. Tan, Inhibition of the c-Jun N-terminal kinase (JNK) signaling pathway by curcumin. Oncogene, 1998. 17(2): p. 173-8.

247. Suh, H.W., S. Kang, and K.S. Kwon, Curcumin attenuates glutamate-induced HT22 cell death by suppressing MAP kinase signaling. Mol Cell Biochem, 2007. 298(1-2): p. 187-94.

248. Xiao, B., et al., Oral administration of $\mathrm{pH}$-sensitive curcumin-loaded microparticles for ulcerative colitis therapy. Colloids Surf B Biointerfaces, 2015. 135: p. 379-85.

249. Mascaraque, C., et al., Rutin has intestinal antiinflammatory effects in the CD4+CD62L+T cell transfer model of colitis. Pharmacol Res, 2014.

250. Wu, S.L., et al., Vanillin improves and prevents trinitrobenzene sulfonic acid-induced colitis in mice. J Pharmacol Exp Ther, 2009. 330(2): p. 370-6.

251. Matsuda, C., et al., Therapeutic effect of a new immunosuppressive agent, everolimus, on interleukin-10 gene-deficient mice with colitis. Clin Exp Immunol, 2007. 148(2): p. 348-59.

252. Park, S., et al., Protective effect of 7-O-succinyl macrolactin A against intestinal inflammation is mediated through PI3-kinase/Akt/mTOR and NF-kappaB signaling pathways. Eur J Pharmacol, 2014. 735: p. 184-92.

253. Xiao, H.T., et al., Inhibitory effect of the gallotannin corilagin on dextran sulfate sodium-induced murine ulcerative colitis. J Nat Prod, 2013. 76(11): p. 2120-5.

254. Terajima, M., et al., Anti-inflammatory effect and selectivity profile of AS1940477, a novel and potent p38 mitogen-activated protein kinase inhibitor. Eur J Pharmacol, 2013. 698(1-3): p. 45562.

255. Kankuri, E., et al., Suppression of pro-inflammatory cytokine release by selective inhibition of inducible nitric oxide synthase in mucosal explants from patients with ulcerative colitis. Scand $\mathbf{J}$ Gastroenterol, 2003. 38(2): p. 186-92. 
1240

1241

1242

1243

1244

1245

1246

1247

1248

1249

1250

1251

1252

1253

1254

1255

1256

1257

1258

1259

1260

1261

1262

1263

1264

1265

1266

1267

1268

1269

1270

1271

1272

1273

1274

1275

1276

1277

1278
256. Singh, K., et al., The apolipoprotein E-mimetic peptide COG112 inhibits NF-kappaB signaling, proinflammatory cytokine expression, and disease activity in murine models of colitis. J Biol Chem, 2011. 286(5): p. 3839-50.

257. Singer, M., G. Trugnan, and M.K. Chelbi-Alix, Arsenic trioxide reduces 2,4,6-trinitrobenzene sulfonic acid-induced murine colitis via nuclear factor-kappaB down-regulation and caspase-3 activation. Innate Immun, 2011. 17(4): p. 365-74.

258. Keerthy, H.K., et al., Novel Synthetic Biscoumarins Target Tumor Necrosis Factor-alpha in Hepatocellular Carcinoma In Vitro and In Vivo. J Biol Chem, 2014.

259. Dotan, I., et al., A randomised placebo-controlled multicentre trial of intravenous semapimod HCl for moderate to severe Crohn's disease. Gut, 2010. 59(6): p. 760-6.

260. Arab, H.H., et al., Telmisartan attenuates colon inflammation, oxidative perturbations and apoptosis in a rat model of experimental inflammatory bowel disease. PLoS One, 2014. 9(5): p. e97193.

261. Kruis, W., et al., Maintaining remission of ulcerative colitis with the probiotic Escherichia coli Nissle 1917 is as effective as with standard mesalazine. Gut, 2004. 53(11): p. 1617-23.

262. Vandenbroucke, K., et al., Orally administered L. lactis secreting an anti-TNF Nanobody demonstrate efficacy in chronic colitis. Mucosal Immunol, 2010. 3(1): p. 49-56.

263. Braat, H., et al., A phase I trial with transgenic bacteria expressing interleukin-10 in Crohn's disease. Clin Gastroenterol Hepatol, 2006. 4(6): p. 754-9.

264. Hayashi, A., et al., A single strain of Clostridium butyricum induces intestinal IL-10-producing macrophages to suppress acute experimental colitis in mice. Cell Host Microbe, 2013. 13(6): p. $711-22$.

265. Thomas, S., et al., Anti-inflammatory effects of Saccharomyces boulardii mediated by myeloid dendritic cells from patients with Crohn's disease and ulcerative colitis. Am J Physiol Gastrointest Liver Physiol, 2011. 301(6): p. G1083-92.

266. Selvam, R., et al., Effect of Bacillus subtilis PB6, a natural probiotic on colon mucosal inflammation and plasma cytokines levels in inflammatory bowel disease. Indian J Biochem Biophys, 2009. 46(1): p. 79-85.

267. Zhang, M., et al., Faecalibacterium prausnitzii Inhibits Interleukin-17 to Ameliorate Colorectal Colitis in Rats. PLoS One, 2014. 9(10): p. e109146.

268. Nishitani, Y., et al., Lactococcus lactis subsp. cremoris FC alleviates symptoms of colitis induced by dextran sulfate sodium in mice. Int Immunopharmacol, 2009. 9(12): p. 1444-51.

269. Lee, J.H., et al., Lactobacillus suntoryeus inhibits pro-inflammatory cytokine expression and TLR-4-linked NF-kappaB activation in experimental colitis. Int J Colorectal Dis, 2009. 24(2): p. 231-7.

270. Matsumoto, S., et al., A component of polysaccharide peptidoglycan complex on Lactobacillus induced an improvement of murine model of inflammatory bowel disease and colitis-associated cancer. Immunology, 2009. 128(1 Suppl): p. e170-80. 
Table I Current and emerging biopharmaceutical therapies in inflammatory bowel disease which are established in clinical stage

\begin{tabular}{|c|c|c|c|c|c|c|}
\hline Drug & $\begin{array}{l}\text { Molecular } \\
\text { Weight (kDa) }\end{array}$ & $\begin{array}{l}\text { Mechanism of } \\
\text { action }\end{array}$ & Status/Brand name & Company & $\begin{array}{l}\text { Route of } \\
\text { administration }\end{array}$ & Indication \\
\hline Infliximab & 144.19 & TNF- $\alpha$ inhibitor & Marketed/Remicade ${ }^{\circledR}$ & Janssen Biotech & iv & $\mathrm{UC}, \mathrm{CD}$ \\
\hline $\begin{array}{l}\text { Certolizumab } \\
\text { pegol }\end{array}$ & 90.8 & TNF- $\alpha$ inhibitor & Marketed/Cimzia ${ }^{\circledR}$ & UCB & $\mathrm{sc}$ & $\mathrm{CD}$ \\
\hline Golimumab & 147 & TNF- $\alpha$ inhibitor & Marketed/Simponi ${ }^{\circledR}$ & Janssen Biotech/MSD & $\mathrm{sc}$ & $\mathrm{UC}$ \\
\hline AVX-470 & - & TNF- $\alpha$ inhibitor & Completed phase-Ib & Avaxia Biologics & oral & $\mathrm{UC}, \mathrm{CD}$ \\
\hline AG014 & - & $\begin{array}{l}\text { L.Lactis secreting } \\
\text { TNF- } \alpha \text { inhibitor }\end{array}$ & Completed phase I & ActoGeniX & oral & $\mathrm{UC}$ \\
\hline
\end{tabular}




\begin{tabular}{|c|c|c|c|c|c|c|}
\hline Natalizumab & 149 & $\begin{array}{l}\text { CAM } \alpha 4 \text {-integrin } \\
\text { inhibitor }\end{array}$ & Marketed/Tysabri ${ }^{\circledR}$ & Biogen & iv & $\mathrm{CD}$ \\
\hline Vatelizumab & - & $\begin{array}{l}\alpha 2 \beta 1 \text {-integrin } \\
\text { inhibitor }\end{array}$ & Phase IIa & Sanofi & $\mathrm{sc}$ & $\mathrm{UC}$ \\
\hline AMG 181 & 144 & $\begin{array}{l}\text { MAdCAM-1 } \\
\text { inhibitor }\end{array}$ & Phase II & $\begin{array}{l}\text { Amgen/AstraZeneca } \\
\text { Plc. }\end{array}$ & $\mathrm{sc}$ & $\mathrm{UC}, \mathrm{CD}$ \\
\hline $\begin{array}{l}\text { Alicaforsen } \\
\text { (ISIS 2302) }\end{array}$ & 6.36 & ICAM-1 inhibitor & Completed phase II & $\begin{array}{l}\text { Atlantic } \\
\text { healthcare/Isis } \\
\text { Pharmaceuticals }\end{array}$ & rectal & $\mathrm{UC}$ \\
\hline
\end{tabular}




\begin{tabular}{|c|c|c|c|c|c|c|}
\hline \multicolumn{7}{|c|}{ Interleukin inhibitors } \\
\hline Low dose IL-2 & 17.6 & $\begin{array}{l}\text { Selective stimulation } \\
\text { of regulatory T cells }\end{array}$ & Phase II & ILTOO Pharma & sc & $\mathrm{UC}, \mathrm{CD}$ \\
\hline Daclizumab & 142.6 & $\begin{array}{l}\text { CD25 (IL-2R } \alpha) \\
\text { inhibitor }\end{array}$ & Completed phase II & Facet Biotech & iv & UC \\
\hline PF04236921 & - & IL-6 inhibitor & Phase II & Pfizer & $\mathrm{sc}$ & $\mathrm{CD}$ \\
\hline Tralokinumab & 143.87 & IL-13 inhibitor & Completed phase II & $\begin{array}{l}\text { AstraZeneca } \\
\text { Plc./Medimmune }\end{array}$ & $\mathrm{sc}$ & UC \\
\hline Anrukinzumab & 145.4 & IL-13 inhibitor & Completed Phase II & Pfizer & iv & UC \\
\hline GSK1070806 & - & IL-18 inhibitor & Completed phase I & GSK & iv & $\mathrm{UC}, \mathrm{CD}$ \\
\hline Ustekinumab & 145.64 & $\begin{array}{l}\text { IL-12/23p40 } \\
\text { inhibitor }\end{array}$ & Phase III & Janssen Biotech & $\mathrm{iv}, \mathrm{sc}$ & $\mathrm{CD}$ \\
\hline
\end{tabular}




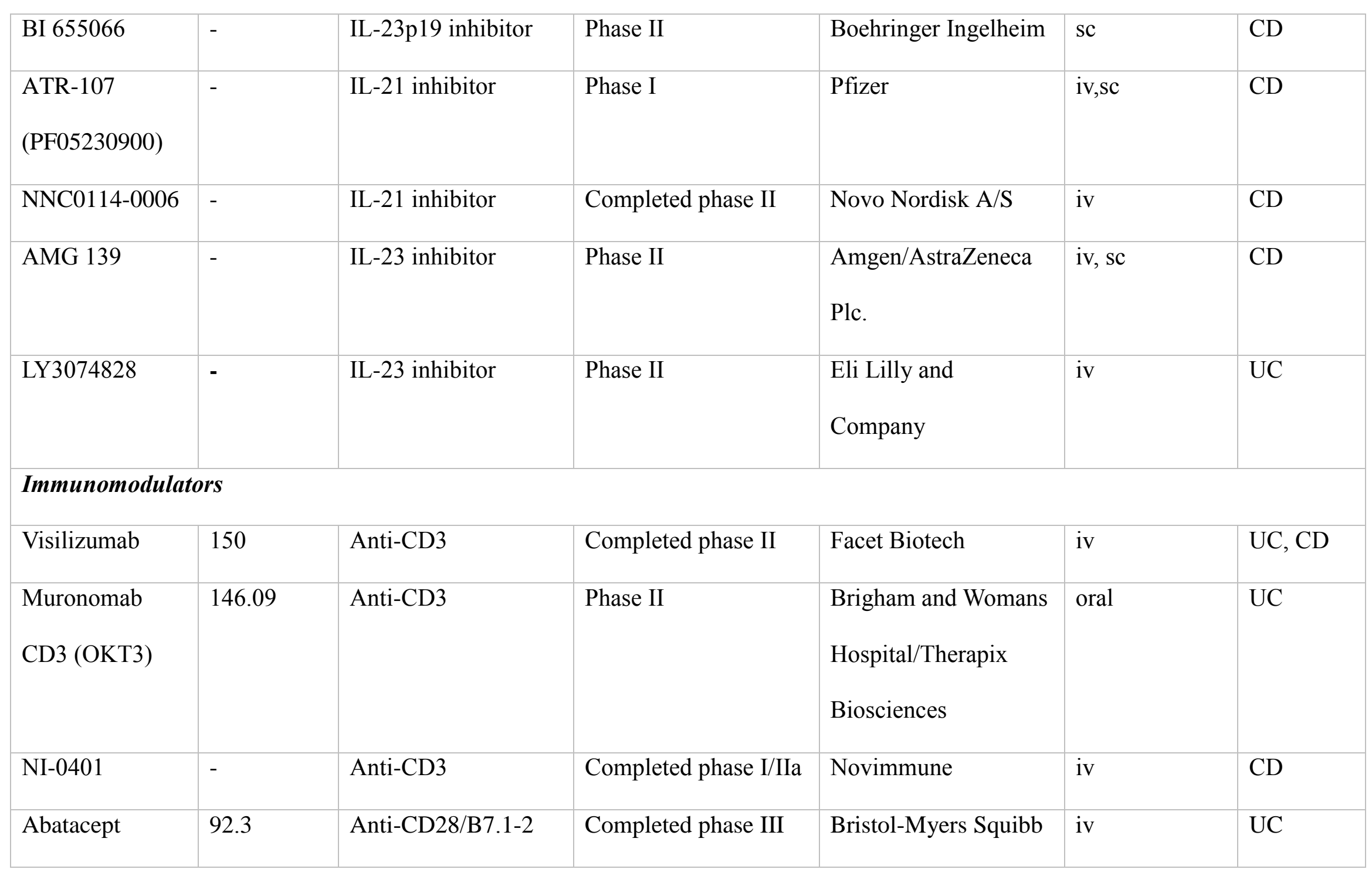




\begin{tabular}{|c|c|c|c|c|c|c|}
\hline FFP104 & - & Anti-CD40 & Phase I/II & FF Pharma & iv & $\mathrm{CD}$ \\
\hline $\begin{array}{l}\text { Ciclosporin } \\
\left(\mathrm{CyCol}^{\circledR}\right)\end{array}$ & 1.202 & $\mathrm{~T}$ cell inhibitor & Completed phase IIa & Sigmoid Pharma & oral & $\mathrm{UC}$ \\
\hline $\begin{array}{l}\text { Ciclosporin } \\
\left(\text { CyCron }^{\circledR}\right)\end{array}$ & 1.202 & $\mathrm{~T}$ cell inhibitor & Completed phase I & Sigmoid Pharma & oral & $\mathrm{CD}$ \\
\hline $\begin{array}{l}\text { P28GST } \\
\text { (glutathione S- } \\
\text { transferase) }\end{array}$ & 28 & $\begin{array}{l}\text { Th1 response } \\
\text { inhibitor; Th2 and } \\
\text { regulatory response } \\
\text { inducer }\end{array}$ & Phase II & $\begin{array}{l}\text { University Hospital, } \\
\text { Lille }\end{array}$ & injection & $\mathrm{CD}$ \\
\hline RDP-58 & 1.38 & $\begin{array}{l}\text { TNF- } \alpha, \text { IFN- } \gamma, \text { IL-2 } \\
\text { and IL-12 inhibitor }\end{array}$ & Completed phase II & Abbott & oral & $\mathrm{UC}, \mathrm{CD}$ \\
\hline $\begin{array}{l}\text { Mongersen } \\
\text { (GED-0301) }\end{array}$ & - & SMAD7 inhibitor & Phase III & Celgene Corporation & oral & $\mathrm{CD}$ \\
\hline
\end{tabular}




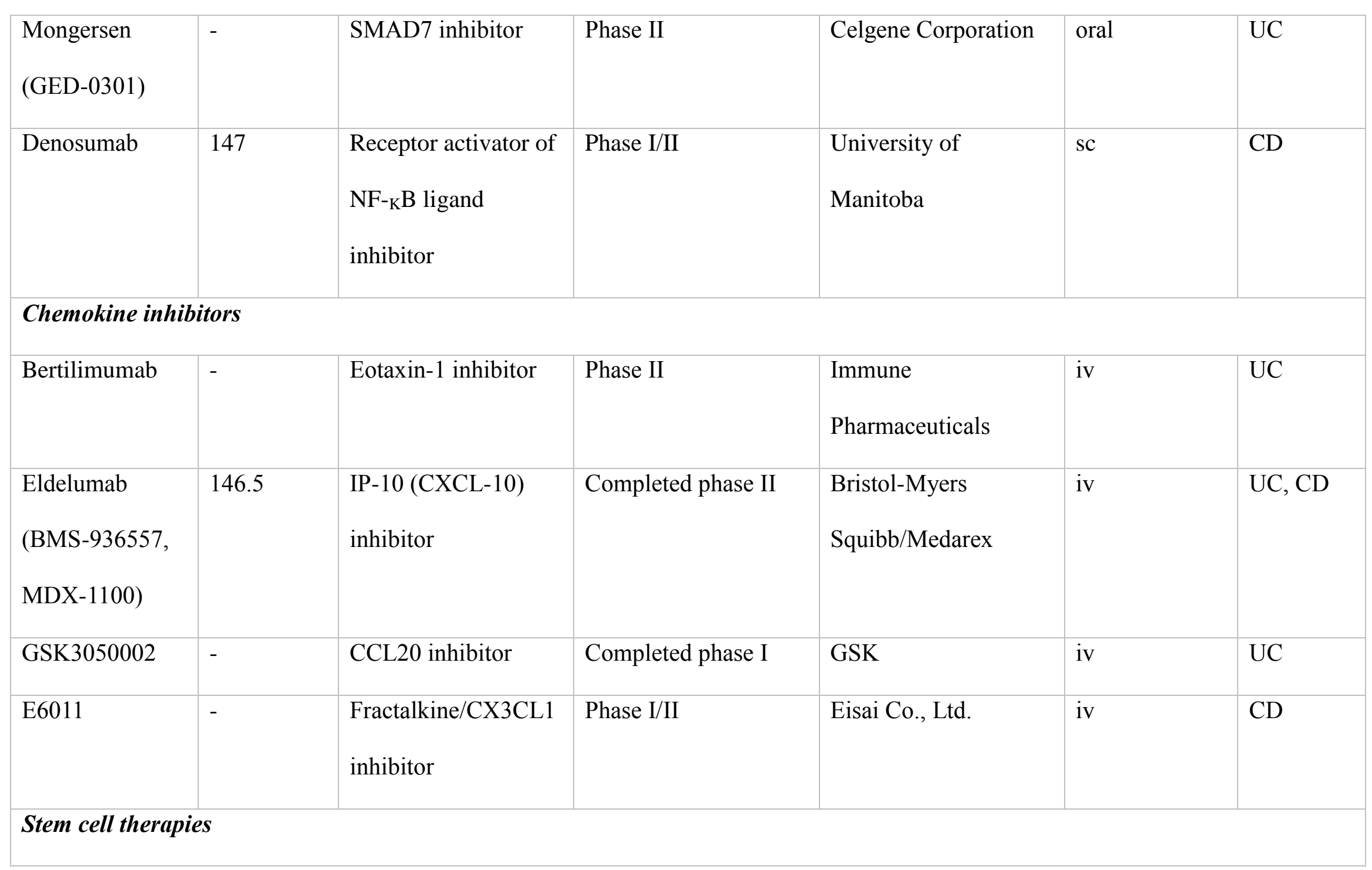




\begin{tabular}{|c|c|c|c|c|c|c|}
\hline $\begin{array}{l}\text { Remestemcel-L } \\
\left(\text { Prochymal }^{\circledR}\right)\end{array}$ & - & Adult stem cells & Phase III & Osiris Therapeutics & iv & $\mathrm{CD}$ \\
\hline ALLO-ASC & - & $\begin{array}{l}\text { Allogeneic adipose- } \\
\text { derived MSCs }\end{array}$ & Phase I & Anterogen Co., Ltd. & iv & $\mathrm{CD}$ \\
\hline PF-05285401 & - & $\begin{array}{l}\text { Adult adherent stem } \\
\text { cells }\end{array}$ & Completed Phase II & Pfizer/Athersys & iv & $\mathrm{UC}$ \\
\hline \multicolumn{7}{|c|}{ Enzyme inhibitors } \\
\hline GS-5745 & - & MMP9 inhibitor & Phase II & Gilead Sciences & $\mathrm{sc}$ & $\mathrm{UC}, \mathrm{CD}$ \\
\hline
\end{tabular}




\begin{tabular}{|c|c|c|c|c|c|c|}
\hline KHK4083 & - & $\begin{array}{l}\text { OX40 (CD134) } \\
\text { inhibitor }\end{array}$ & Phase II & $\begin{array}{l}\text { Kyowa Hakko Kirin } \\
\text { Pharma Inc. }\end{array}$ & iv & $\mathrm{UC}$ \\
\hline Dolcanatide & 1.68 & $\begin{array}{l}\text { Guanylate cyclase-C } \\
\text { agonist }\end{array}$ & Completed phase Ib & $\begin{array}{l}\text { Synergy } \\
\text { Pharmaceuticals }\end{array}$ & oral & $\mathrm{UC}$ \\
\hline \multicolumn{7}{|l|}{ TLR agonists } \\
\hline BL-7040 & - & $\begin{array}{l}\text { TLR-9 agonist and } \\
\text { acetylcholinesterase } \\
\text { inhibitor }\end{array}$ & Completed phase IIa & BioLineRx, Ltd. & oral & $\mathrm{UC}$ \\
\hline \multicolumn{7}{|l|}{ Probiotics } \\
\hline AG011 & - & $\begin{array}{l}\text { Probiotic of L.Lactis } \\
\text { secreting IL-10 }\end{array}$ & Completed phase I & ActoGeniX & oral & $\mathrm{UC}$ \\
\hline
\end{tabular}




\begin{tabular}{|c|c|c|c|c|c|c|}
\hline VSL\#3 & - & $\begin{array}{l}\text { Probiotic of } 8 \\
\text { bacterial strains, } \\
\text { protects epithelial } \\
\text { barrier function }\end{array}$ & Phase IV & VSL Pharmaceuticals & oral & $\mathrm{UC}, \mathrm{CD}$ \\
\hline $\begin{array}{l}\text { Bovine } \\
\text { intestinal } \\
\text { alkaline } \\
\text { phosphatase }\end{array}$ & $140-160$ & LPS inhibitor & Completed phase II & AM-Pharma & oral & $\mathrm{UC}$ \\
\hline $\begin{array}{l}\text { SB012 } \\
\text { (DNAzyme } \\
\text { hgd40) }\end{array}$ & - & GATA-3 inhibitor & Phase I/II & $\begin{array}{l}\text { Sterna Biologicals } \\
\text { GmbH \& Co. KG }\end{array}$ & rectal enema & $\mathrm{UC}$ \\
\hline \multicolumn{7}{|c|}{ GLP receptor agonist } \\
\hline ZP1848 & - & GLP-2 agonist & Completed phase Ia & ZealandPharma & $\mathrm{sc}$ & $\mathrm{CD}$ \\
\hline
\end{tabular}


and $\mathrm{Ib}$

TNF, tumor necrosis factor; IFN, interferon; CAM, cell adhesion molecule; ICAM, intercellular adhesion molecule; MAdCAM, mucosal vascular addressin cell adhesion molecule; IL, interleukin; GLP, glucagon-like peptide, sc, subcutaneous; iv, intravenous; il, intralesional; ic: intracolonic 
Table II Pathophysiological changes in the gut of ulcerative colitis and Crohn's disease patients as compared to healthy volunteers.

\begin{tabular}{lll}
\hline Healthy & Ulcerative colitis & Crohn's disease \\
\hline
\end{tabular}

Luminal $\mathrm{pH}$

Small Intestine

$6.1-7.0^{[206]}$

$6.1-8.3^{[207,208]}$

$6.0-7.4^{[208,209]}$

Colon

$5.8-7.7^{[206]}$

$2.3-7.5^{[207,208]}$

$5.2-7.0^{[208,209]}$

Transit time (hrs)

Small Intestine

$1.5-5.4^{[206]}$

$5.6 \pm 2.4^{[210], \mathrm{a}}$

$1.8-6.6^{[211], b}$

Colon

$41.1-62.3^{[212]}$

$9.5-39.1^{[212]}$

N.C

Bacterial flora

Small Intestine

Duodenum

$10^{2}$

N.C

microorganisms/gram

luminal content ${ }^{[213]}$

Jejunum

$10^{2}$

N.C

microorganisms/gram

luminal content ${ }^{[213]}$

$\begin{array}{ll}\text { Ileum } & 10^{7}-10^{8} \quad \text { N.C } \\ & \text { microorganisms/gram } \\ & \text { luminal content }\end{array}$

Faecalibacterium

prausnitzii $^{[214]}$

Enterobacteriaceae $^{[215]} \uparrow$

E. coli $^{[215]} \uparrow$ 
Colon

Lipopolysaccharides

(LPS) in colonic lumen

$$
10^{11}-10^{12} \mathrm{CFU} / \mathrm{ml}^{[216]}
$$

Ruminococcus spp
Eubacterium spp $p^{[10], d}$

Fusobacterium $\operatorname{spp}^{[10], d}$

Lactobacillus spp ${ }^{[10], d}$

Proteobacteria $^{[10], d}$

Bacteroidetes $^{[10], d}$

$\sim 50 \mu \mathrm{g} / \mathrm{ml}^{[217]}$

N.C ${ }^{[217]}$

Intestinal alkaline

phosphatase

Colon

$1.0 \pm 0.1$ units $/ \mathrm{mg}^{[218]}$

2.8-fold decrease ${ }^{[219]}$

2.4-fold decrease ${ }^{[219]}$

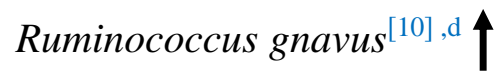

Faecalibacter $_{\text {prausnitziid }^{[10}}$ Bacteroidetes
Bifidobacteriu
Firmicutes $^{[10]}$
Enterobacteriace $^{\text {Ruminococcus }}$
Increased $^{[217]}$ 
Intestinal barrier function N.C

Colonic mucus layer

N.C

$\begin{array}{ll}\text { Widening of barrier } & 2 \text { to } 3 \text {-fold increase in } \\ \text { tight junctions leading } & \text { intestinal permeability, } \\ \text { to increased } & \text { reduced levels of anti- } \\ \text { permeability }^{[220]} & \text { microbial defensins }\end{array}{ }^{[221-223]}$

Decreased thickness $^{[220]} \quad$ Increased thickness $^{[224,225]}$

Goblet cell count $^{[33]} \downarrow \quad$ Goblet cell count $^{[33]} \boldsymbol{\uparrow}$

Trefoil factor $3 \uparrow \quad$ Trefoil factor $3\left(\right.$ TFF3) ${ }^{[33]} \uparrow$

$(\mathrm{TFF} 3)^{[33]}$

MUC2, MUC3 and MUC4 $\uparrow$

\begin{tabular}{l|l} 
MUC2 and MUC3 $^{\text {glycoproteins }^{[33]}}$ & $\begin{array}{l}\text { Glycoproteins }^{[33]} \\
\alpha \text {-defensins HD5, HD6 }\end{array}$ \\
& $\beta$-defensins HBD1, HBD2, \\
& HBD3 and HBD4 $4^{[224], \mathrm{f}}$
\end{tabular}
Immune cells

N.C
Mast cells ${ }^{[225]}$

T-cells $^{[12,14]}$

Neutrophils $^{[12,14]}$

Macrophages $^{[12,14]}$
Mast cells ${ }^{[15,33,224-226]}$

Macrophages $^{[226]}$

Eosinophils/secreted

proteins $^{[226]}$ 
Eosinophils/secreted Basophils ${ }^{[226]}$

proteins $^{[12,14]}$

Colonic mucosal

immunoglobulins (Ig)
$\operatorname{Ig} A$
N.C ${ }^{[44]}$
Decreased $^{[44]}$
N.C ${ }^{[44]}$
$\operatorname{Ig} G$
$3 \mu \mathrm{g} / \mathrm{ml}^{[45], \mathrm{g}}$
$512 \mu \mathrm{g} / \mathrm{ml}^{[44], \mathrm{h}}$
$256 \mu \mathrm{g} / \mathrm{ml}^{[44], \mathrm{h}}$
$I g G 1$
$1.8 \mu \mathrm{g} / \mathrm{ml}^{[45], \mathrm{g}}$
$479 \mu \mathrm{g} / \mathrm{ml}^{[44], \mathrm{h}}$
$121 \mu \mathrm{g} / \mathrm{ml}^{[44], \mathrm{h}}$
$\operatorname{Ig} G 2$
$1.3 \mu \mathrm{g} / \mathrm{ml}^{[45], \mathrm{g}}$
N.C
$185 \mu \mathrm{g} / \mathrm{ml}^{[44], \mathrm{h}}$
$\operatorname{Ig} G 3$
$0.2 \mu \mathrm{g} / \mathrm{ml}^{[45], \mathrm{g}}$
$51 \mu \mathrm{g} / \mathrm{ml}^{[44], \mathrm{h}}$
$36 \mu \mathrm{g} / \mathrm{ml}^{[44], \mathrm{h}}$

Transferrin receptor

N.C

Increased

Increased expression $^{[227]}$

expression

$\operatorname{expression}^{[227]}$

Neonatal Fc receptor

N.C

Increased expression ${ }^{[59]}$

Increased expression $^{[59]}$

(FcRn)

Cytokines N.C

Proinflammatory

Proinflammatory

cytokines $^{[17,102,228-230]}:$ cytokines $^{[6,63,230,232-234]}$ :

IFN- $\gamma$
TNF- $\alpha$
IL-5




\begin{tabular}{|c|c|c|c|}
\hline & & IL-12 & IL-16 \\
\hline & & IL-13 & IL-17 \\
\hline & & IL-18 & IL-18 \\
\hline & & IL-23 & IL-21 \\
\hline & & IL-27 & IL-27 \\
\hline & & Pro-regulatory & Pro-regulatory cytokines ${ }^{[6,}$ \\
\hline & & cytokines $[6,63,155,230$, & 63, 155, 230, 231]: \\
\hline & & 231]: & IL-4 $\downarrow$ \\
\hline & & $\mathrm{IL}-4 \downarrow$ & $\mathrm{IL}-10 \downarrow$ \\
\hline & & $\mathrm{IL}-10 \downarrow$ & TGF- $\beta 1 \downarrow$ \\
\hline & & TGF- $\beta 1 \uparrow$ & \\
\hline Interferon gamma-induced & N.C & 5.98-fold higher & 4.76-fold higher \\
\hline protein (IP-10)/CXCL-10 & & expression $^{[235], \mathrm{i}}$ & expression $^{[235], \mathrm{i}}$ \\
\hline Natural killer activating & N.C & N.C ${ }^{[236], i}$ & Upregulation of $\mathrm{CD}^{+}{ }^{+} \mathrm{T}$ \\
\hline receptor 2D (NKG2D) & & & cells expressing \\
\hline & & & NKG2D ${ }^{[236], i}$ \\
\hline GATA-3 and STAT-4 & N.C & Increased & N.C $C^{[11], i}$ \\
\hline signalling proteins & & $\operatorname{expression}^{[11], \mathrm{i}}$ & \\
\hline OX40 (CD134) & No colonic lamina & Increased colonic & Increased colonic lamina \\
\hline & propria expression $^{[85]}$ & lamina propria & propria expression ${ }^{[85]}$ \\
\hline
\end{tabular}

Enzymes

Colon tissue

N.C

Guanylate cyclase- $\mathrm{C}^{[91]} \downarrow$ Guanylate cyclase- $\mathrm{C}^{[91]}$ 


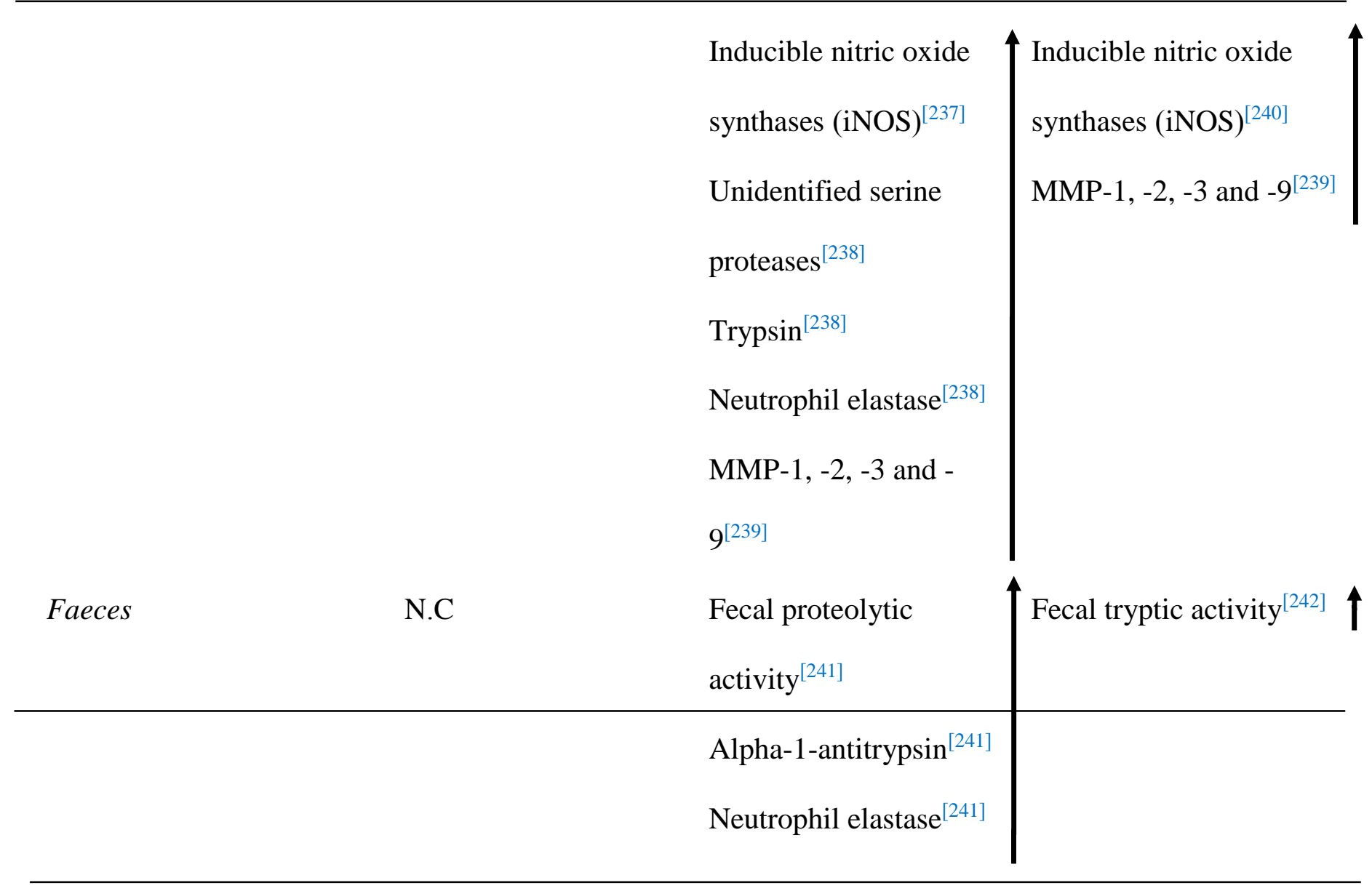

Toll-like receptors (TLRs) Low expression of Increased expression of Increased expression of TLR-2 and TLR-4; TLR-2, TLR-4 and TLR-2, TLR-4 and CD20

High expression of TLR-5 by intestinal cells by intestinal and TLR-3 and TLR- $\quad$ dendritic cells ${ }^{[10,149]} \quad$ colonic dendritic cells $^{[10,149]}$

$5^{[150], j} \quad$ No change in TLR-3 Lower expression of TLR-

expression $^{[150], \mathrm{k}} \quad 3^{[150], \mathrm{k}}$

Heat shock proteins (HSP) N.C
$\operatorname{HSP} 27^{[243]} \downarrow$
HSP $27^{[243]} \downarrow$
HSP70 ${ }^{[243]}$
HSP70 ${ }^{[243]}$ 
$\mathrm{NC}$, no change; ${ }^{a}$ measured using mesalazine microspheres; ${ }^{\mathrm{b}}$ measured using $\mathrm{pH}$ sensitive capsule; ${ }^{\mathrm{c}}$ mucosal sample; ${ }^{\mathrm{d}}$ fecal sample; ${ }^{\mathrm{e}}$ ileal $\mathrm{CD} ;{ }^{\mathrm{f}}$ colonic $\mathrm{CD}$; ${ }^{\mathrm{g}}$ intestinal mononuclear cells; ${ }^{\mathrm{h}}$ colonic washings taken at endoscopy; ${ }^{\mathrm{i}}$ expression levels in colon tissue compared to non-IBD subjects; intestinal biopsies from non-IBD subjects; kintestinal biopsies from UC and CD patients; IFN, interferon; TNF- $\alpha$, tumor necrosis factor alpha; TGF- $\beta 1$, transforming growth factor beta 1; IL, interleukin; IP-10, interferon- $\gamma$-inducible-protein-10; $\mathrm{MCP}$, monocyte chemoattractant protein; MIP, macrophage inflammatory protein; MMP, Matrix metalloproteinases; STAT-4, signal transducer and activator of transcription-4; SMAD-7, Mothers against decapentaplegic homolog 7; enhanced; reduced. 
Table III Cutting edge in novel anti-inflammatory molecules that function via suppression of cytokines through inhibition of signaling pathways

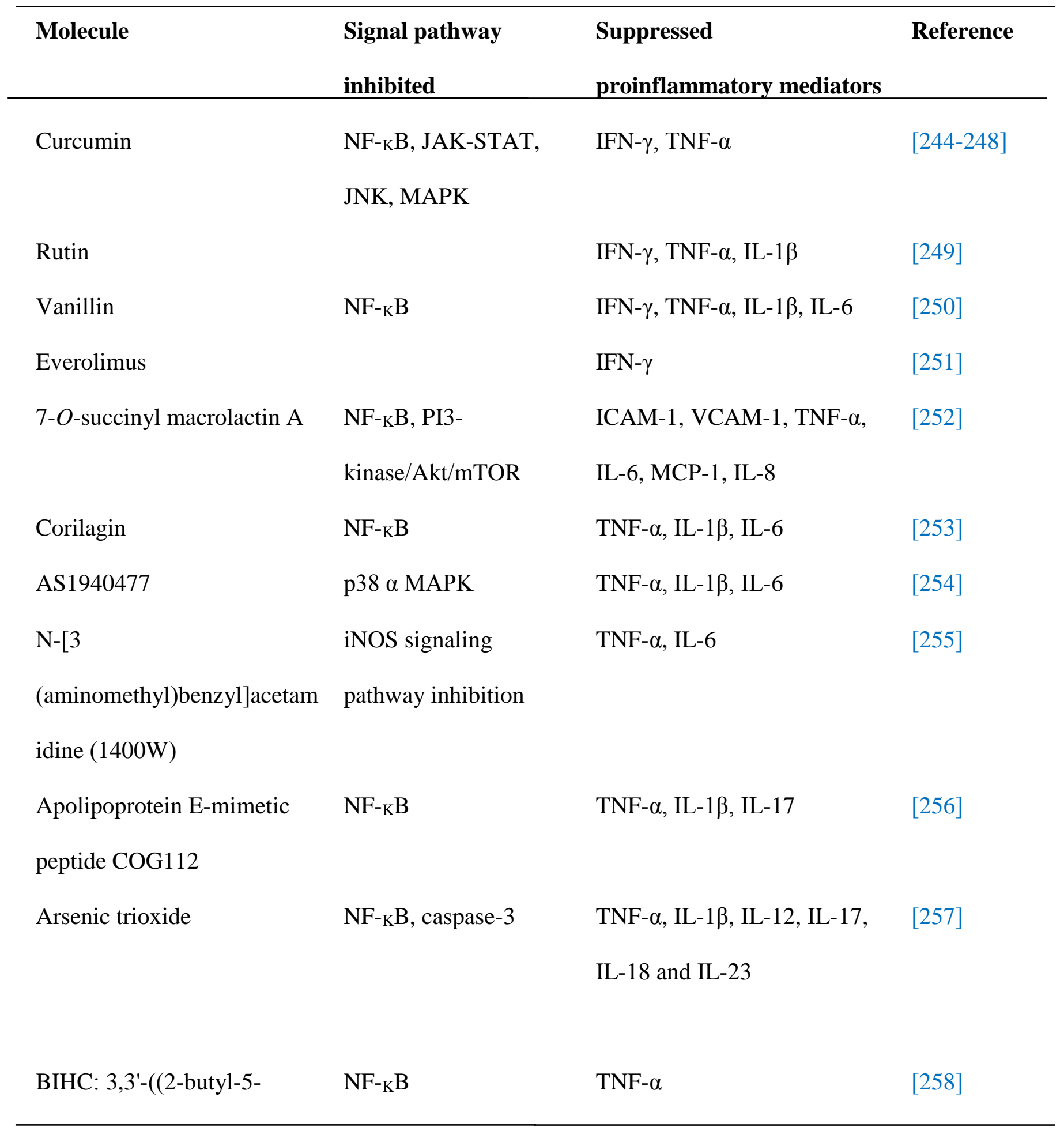


chloro-1H-imidazol-4-

yl)methylene)bis(4-hydroxy-

2H-chromen-2-one)

Semapimod

MAPK (p38 and JNK) TNF- $\alpha$, IL-1 $\beta$, IL-6, MIP-

Telmisartan

$\mathrm{NF}_{\mathrm{K}} \mathrm{B}$

$1 \alpha, \beta$,

[260]

TNF- $\alpha$ 
Table IV Promising probiotic approaches proposed to be potential novel treatment of IBD

\begin{tabular}{|c|c|c|c|}
\hline Strain & Mechanism of action & Indication & Reference \\
\hline Escherichia coli & Induction of anti-microbial & UC & [261] \\
\hline Nissle 1917 & $\begin{array}{l}\text { defensins, inhibition of adhesion } \\
\text { of pathogens }\end{array}$ & & \\
\hline Lactococcus lactis & Secretion of anti-TNF- $\alpha$ antibodies & $\mathrm{UC}, \mathrm{CD}$ & {$[262]$} \\
\hline \multicolumn{4}{|l|}{ genetically modified } \\
\hline Lactococcus lactis (LL- & Secretion of IL-10 & $\mathrm{CD}$ & {$[263]$} \\
\hline \multicolumn{4}{|l|}{ Thy12) genetically } \\
\hline \multicolumn{4}{|l|}{ modified } \\
\hline Clostridium butyricum & Induction of IL-10 production & $\mathrm{UC}$ & {$[264]$} \\
\hline Saccharomyces & Decreases secretion of TNF- $\alpha$ and & $\mathrm{UC}, \mathrm{CD}$ & {$[265]$} \\
\hline boulardii & IL-6, increases IL-8 secretion & & \\
\hline \multirow[t]{2}{*}{ Bacillus subtilis PB6 } & $\begin{array}{l}\text { Inhibits phospholipase A2, } \\
\text { decreased expression of IFN- } \gamma \text {, }\end{array}$ & $\mathrm{UC}, \mathrm{CD}$ & {$[266]$} \\
\hline & TNF- $\alpha$, IL-1 $\beta$, IL-6 & & \\
\hline
\end{tabular}




\begin{tabular}{|c|c|c|c|}
\hline Faecalibacterium & Inhibition of IL-17 and increase in & $\mathrm{UC}, \mathrm{CD}$ & [267] \\
\hline prausnitzii & IL-10 and IL-12 & & \\
\hline Lactococcus lactis & $\mathrm{NF}_{-\mathrm{K}} \mathrm{B}$ inhibition, decrease in & $\mathrm{UC}, \mathrm{CD}$ & [268] \\
\hline \multirow[t]{2}{*}{ subsp. cremoris FC } & TNF- $\alpha$, IL-6, IL- 8 , iNOS and & & \\
\hline & MIP-2 & & \\
\hline Lactobacillus & TLR-4-linked NF-KB inhibition, & $\mathrm{UC}, \mathrm{CD}$ & [269] \\
\hline suntoryeus (Lactic acid & decrease in TNF- $\alpha$, IL- $1 \beta$, IL-6 & & \\
\hline bacteria) & and $\mathrm{COX}-2$ & & \\
\hline Lactobacillus casei & Suppression of IL-6 via NF-KB & $\mathrm{UC}, \mathrm{CD}$ & {$[270]$} \\
\hline Shirota & signaling pathway inhibition & & \\
\hline
\end{tabular}

